\title{
Review of Effluents and Health Effects of Cooking and the Performance of Kitchen Ventilation
}

\author{
Yujiao Zhao ${ }^{1,2^{*}}$, Lang Liu ${ }^{1,2^{* *}}$, Pengfei Tao ${ }^{3}$, Bo Zhang ${ }^{1,2}$, Chao Huan ${ }^{1,2}$, Xiaoyan Zhang ${ }^{1,2}$, \\ Mei Wang ${ }^{1,2}$ \\ ${ }^{1}$ College of Energy Engineering, Xi'an University of Science and Technology, Xi'an, Shaanxi 710054, China \\ ${ }^{2}$ Key Laboratory of Western Mines and Hazards Prevention, Ministry of Education of China, Xi'an 710054, China \\ ${ }^{3}$ Key Laboratory of Coal Resources Exploration and Comprehensive Utilization, Ministry of Land and Resources, Xi'an \\ 710021, China
}

\begin{abstract}
Cooking effluents are one of the most important sources of pollution in the indoor and outdoor environment. Exposure to cooking oil fumes (COFs) can increase the risk of many diseases. A healthy indoor environment and an energy-efficient ventilation system in kitchens are urgently demanded. This review is concerned with the current knowledge of the physical and chemical compositions of aerosols generated from typical cooking processes as reported in the literature. It is focused on the effects of cooking fuel, cooking oil, cooking temperature, cooking method, cooking style and other factors on the characteristics of cooking particles. The improvement measures in kitchen ventilation, supply air strategy and evaluation index for the kitchen environmental protection are also reviewed. It was found that the cooking process emits high concentrations of particulate matter (PM), and inhalable particles account for a high proportion, which may cause serious harm to human body. Coupled with various factors affecting the particle concentrations and particle size distribution, as well as the main chemical components groups used to characterize the cooking particles, include PAHs, fatty acids, dicarboxylic acids, n-alkanes, sterols, monosaccharide anhydrides, metals and ions. Using an appropriate ventilation system and some auxiliary measures can effectively reduce cooking oil fumes pollution.
\end{abstract}

Keywords: Cooking particles; Indoor air quality; Health effect; Kitchen ventilation.

\section{INTRODUCTION}

According to World Health Organization (WHO), each year, approximately 4.3 million people die from indoor air pollutants (WHO, 2014). Cooking oil fumes have been recognized as a significant source of indoor and outdoor pollutants in urban and rural areas (He et al., 2004; See and Balasubramanian, 2008; Xiao et al., 2015; Ni et al., 2016). COFs are aerosols comprising particles, droplets (oil droplets and moisture), and gaseous companion products. In the indoor environment of residential buildings, the main source of fine particulate matter $\left(\mathrm{PM}_{2.5}\right.$, diameter less than or equal to $2.5 \mu \mathrm{m}$ ) with nonsmokers in buildings is cooking (Abt et al., 2000). It was reported that $43.2 \%$ of the

\footnotetext{
* Corresponding author.

Tel.: +86 13759979306; Fax: +862985584131

E-mail address: zhaoyujiao@xust.edu.cn

** Corresponding author.

Tel.: +86 15829310227; Fax: +862985584131

E-mail address: liulang@xust.edu.cn
}

microparticles and $52.5 \%$ of microparticle exposure were from the cooking process (Chowdhury et al., 2012). COFs are also regarded as one of the most important sources of urban atmospheric fine particles (Wallace and Ott, 2011; Wheeler et al., 2011). It has been found that cooking contributes to approximately $7 \%$ of the total particle mass and $10-30 \%$ of organic aerosol in China (He et al., 2004; Wang et al., 2009). In the city of Los Angeles, 20\% of $\mathrm{PM}_{2.5}$ in the atmosphere comes from COFs (Schauer et al., 2000).

Cooking particles have been associated with cardiac, pulmonary, dermal and renal toxic effects (Sjaastad et al., 2008). Many airborne substances that are released from cooking are potentially harmful (Shields et al., 1995). The hazards of cooking particles increase with the rise in the concentration and reduction in the particle size (Chowdhury et al., 2012; Sharma and Balasubramanian, 2018). Ultrafine particles (UFPs, diameter less than or equal to $0.1 \mu \mathrm{m}$ ) have a large specific surface area and are prone to attaching to large numbers of viruses, bacteria, and organic matter (Zhao et al., 2015). UFPs emitted during cooking are thought to cause oxidative stress in lung cells (Beck-Speier et al., 2005) and enhance lung inflammation and allergic 
reactions (Alessandrini et al., 2006). There is a consistent positive correlation between the particulate pollutants released from cooking and risk of lung cancer. This explains why nonsmoking women have a high chance of developing lung cancer in China, the West, and Southeast countries (Seow et al., 2000; Wang et al., 2017; Wang et al., 2019). Previous studies have shown that respiratory diseases, such as rhinitis, emphysema, asthma, abnormal lung function, and increased lung cancer mortality among hotel and restaurant staff, are associated with exposure to COFs (Ko et al., 2000; Svendsen et al., 2002). The poor lung function of chefs can be attributed to a single or a combination of the indoor air pollutants, such as polycyclic aromatic hydrocarbons (PAHs) and carbonyl compounds (Singh et al., 2006; Wong et al., 2011). The International Agency for Research on Cancer classifies COFs from high-temperature frying as "possible human carcinogens" (IARC, 2010).

The potential hazard of COFs depends on exposure, which is a function of concentration and time. Exposure to cooking-related pollutants occur within commercial spaces such as restaurants, commercial kitchens, residences, neighborhoods, and urban areas from the aggregation of cooking emissions. Emissions result from fuel combustion and from food preparation. For fuel, there are large differences among solid, liquid and gaseous fuels and electricity. For food preparation, the cooking activity (cooking method, cooking temperature, and edible oil) and cooking style (Chinese or Western) are important. In this review, we explore information regarding the contamination level of cooking-generated PM and techniques using ventilation to control cooking pollution. To this end, we analyze the physicochemical properties of the cooking particles and summarize the potential effects of those pollutants in relation to their adverse impacts on human health. Moreover, comparative analysis of the factors that influence concentration, chemical composition and propagation of cooking particles is conducted. Finally, the effect of kitchen ventilation on pollution removal is evaluated, involving exhaust hood performance, supply air strategy, and capture efficiency. Thus, this review will help us gain a better understanding of pollutants emitted from cooking, influencing factors, and control strategies.

\section{HEALTH EFFECT OF COOKING}

\section{Cooking Particles}

Cooking process emits high concentrations of particulate matter. Buonanno et al. (2010) sampled particles in 15 pizzerias without a ventilation system. The number of particles produced during the cooking process in the test restaurant ranged from $3 \mathrm{E}+4$ to $6 \mathrm{E}+5$ particles $\mathrm{cm}^{-3}$, and the average concentration was $1.7 \mathrm{E}+5$ particles $\mathrm{cm}^{-3}$. Torkmahalleh et al. (2013) conducted an experiment in a $0.81 \mathrm{~m}^{3}$ laboratory hood operating at $65 \mathrm{~m}^{3} \mathrm{~h}^{-1}$ to study the particulates produced during the heating of seven edible oils. The particle number concentration of $10-500 \mathrm{~nm}$ at $197^{\circ} \mathrm{C}$ was $2.5 \mathrm{E}+5$ to $2.3 \mathrm{E}+6$ particles $\mathrm{cm}^{-3}$. The chamber (with a fan) study conducted by Wang et al. (2018) investigated particle emission characteristics originated from using different types of oil and food materials drew a similar conclusion. In the study of mass concentration, the $\mathrm{PM}_{2.5}$ emitted from five restaurants in China were sampled in the exhaust pipe on the rooftop of the building (Wang et al., 2009). The mass concentration of $\mathrm{PM}_{2.5}$ ranged from 331.3 to $1841.9 \mu^{-3} \mathrm{~m} \mathrm{~m}^{-3}$, which was $4.3-20.2$ times that of the $\mathrm{PM}_{2.5}$ concentration in the surrounding environment. Pei et al. (2016) conducted the test in three commercial restaurants, including those serving Shanghai cuisine, Sichuan cuisine, and Italian cuisine. The test results showed that the $\mathrm{PM}_{2.5}$ concentration at the exit of restaurants' organized emissions purification systems ranged from 325 to $693 \mu \mathrm{g} \mathrm{m}^{-3}$, which was one order of magnitude higher than the background environmental concentration. Gao et al. (2013) sampled the particles in a laboratory kitchen with an exhaust hood. They found that the mass concentration of particles during a 2-min heating process of six edible oils was 2-3 orders of magnitude higher than the background concentration. Chiang et al. (1999) tested particles produced from six edible oils. In the experiment, when $200 \mathrm{~mL}$ of edible oil was heated to $250 \pm 10^{\circ} \mathrm{C}$, the range of the released particle concentration was $20.3-24.2 \mathrm{mg} \mathrm{m}^{-3}$. Zhao et al. (2015) conducted a test in the exhaust pipe of a 9-story apartment building kitchen. During dinner, the average total suspended particles (TSPs) concentration was $138 \mu \mathrm{g} \mathrm{m}^{-3}$.

All of the research results showed that smaller particles occupied a high proportion both in terms of the particle mass concentration and particle number concentration. For the particle mass, Zhao et al. (2007a) conducted tests on four commercial restaurants and found that the ratio of $\mathrm{PM}_{2.5}$ to $\mathrm{PM}_{10}$ (PM with the diameter less than or equal to $10 \mu \mathrm{m}$ ) was approximately $80 \%$. In the test conducted by Lee et al. (2001) $\mathrm{PM}_{2.5}$ in barbecue shops, hot pot restaurants, and pastry shops accounted for $80-93 \%$ of $\mathrm{PM}_{10}$, while the ratio in Western restaurants was lower (less than 60\%). In the test of university cafeterias, particles with a diameter in the ranges of $0.160-0.268 \mu \mathrm{m}$ and $0.390-0.626 \mu \mathrm{m}$ accounted for the largest proportion of the total mass of $\mathrm{PM}_{10}$ (See et al., 2006). Zhao et al. (2007b) tested Western-style fast food restaurants and found that the mass concentration of $\mathrm{PM}_{2.5}$ exceeded $90 \%$ in the mass concentration of $\mathrm{PM}_{10}$. In Gao et al. (2013) test for heating edible oils, the mass of particles in the range of 1.0-5.0 $\mu \mathrm{m}$ accounted for almost $100 \%$ of $\mathrm{PM}_{10}$. In the test conducted by Buonanno et al. (2009) when bacon was roasted, the proportions of UPFs, submicron particles (PM with the diameter less than or equal to $1.0 \mu \mathrm{m})$, and particles with sizes in the range of 1$2.5 \mu \mathrm{m}$ were $5 \%, 67 \%$, and $27 \%$, respectively, among the total mass of $\mathrm{PM}_{10}$. When fries were fried, the above proportion was $9 \%, 67 \%$ and $24 \%$, respectively, indicating that the proportion of $\mathrm{PM}_{1}$ in $\mathrm{PM}_{10}$ was approximately $72-$ $76 \%$. The mass ratios of the particle sizes are shown in Table 1.

Regarding the particle number, Sjaastad et al. (2008) measured the number of particles in the range of $0.3-$ $1.0 \mu \mathrm{m}$. The results showed that the particles were mainly concentrated in the range of $0.3-0.5 \mu \mathrm{m}$, which is consistent 
Table 1. The mass ratio of fine particle and total particles during cooking process.

\begin{tabular}{llll}
\hline Cooking style & Items & Mass ratio & References \\
\hline Chinese commercial & $\mathrm{PM}_{2.5} / \mathrm{PM}_{10}$ & $\sim 0.8$ & Zhao et al., 2007a \\
Chinese commercial & $\mathrm{PM}_{2.5} / \mathrm{PM}_{10}$ & $0.56-0.84$ & Lee et al., 2001 \\
Chinese commercial & $\mathrm{PM}_{2.5} / \mathrm{PM}_{10}$ & $>0.9$ & Zhao et al., 2007b \\
Laboratory kitchen (oil-heating) & $\mathrm{PM}_{1.0-5.0} / \mathrm{PM}_{10}$ & $\sim 1.0$ & Gao et al., 2013 \\
Laboratory kitchen (grilling bacon) & $\mathrm{PM}_{0.1} / \mathrm{PM}_{10}$ & 0.05 & Buonanno et al., 2009 \\
& $\mathrm{PM}_{0.1-1} / \mathrm{PM}_{10}$ & 0.67 & \\
& $\mathrm{PM}_{1-2.5} / \mathrm{PM}_{10}$ & 0.27 & \\
Laboratory kitchen (frying chips) & $\mathrm{PM}_{0.1} / \mathrm{PM}_{10}$ & 0.09 & \\
& $\mathrm{PM}_{0.1-1} / \mathrm{PM}_{10}$ & 0.67 & \\
& $\mathrm{PM}_{1-2.5} / \mathrm{PM}_{10}$ & 0.24 & \\
\hline
\end{tabular}

with the previous study of Abtet et al. (2000). They found that the particles were mainly concentrated in the range of $0.02-0.5 \mu \mathrm{m}$ during frying. Wallace et al. (2008) conducted an intensive measurement and recognized that most of the particles emitted from cooking were less than $10 \mathrm{~nm}$. The peak concentration was approximately $5 \mathrm{~nm}$ to $6 \mathrm{~nm}$. Torkmahalleh et al. (2012) used MSP (Shoreview, MN, USA) to monitor the concentration and particle size distribution of cooking particles. The mode diameters of peanut oil, soybean oil, safflower oil, corn oil, olive oil, coconut oil, and canola oil tested were $16-30 \mathrm{~nm}, 24-82 \mathrm{~nm}$, 20-54 nm, 40-61 nm, 25-88 nm, 16-44 nm and 19-51 nm, respectively. Among them, the number of UPFs accounted for $76-99 \%$ of the total number of particles $(10-500 \mathrm{~nm})$. This is consistent with the previous studies of Wallace et al. (2004), See et al. (2006), Glytso et al. (2010) and Zhao et al. (2019). The ratio of the number of fine particles and total particles is presented in Table 2 .

\section{Chemical Property of Cooking Particles}

COFs contains over 200 chemical components, mainly elemental carbon (EC), organic carbon (OC), and inorganic elements. OC accounts for a larger proportion of cooking particles, which mainly include PAHs, carbonyl compounds and n-alkanes (Wallace et al., 2004; Abdullahi et al., 2013; Pei et al., 2016; Liu et al., 2017; Zhao et al., 2019). Other ingredients make up less of the cooking particle concentration (Ng et al., 2001). The adverse health effects caused by cooking particle is not only related to its physical properties (e.g., particle number, particle size, and total surface area) but also related to the chemical compositions of PM (Rajasekar and Balasubramanian, 2001; Oeder et al., 2012).

PAHs refer to organic compounds containing two or more benzene rings. During cooking, PAHs are mainly derived from pyrolysis products of unsaturated fatty acids under high temperature (Chiang et al., 1999; Chen et al., 2019). PAHs occupies only a very small part of cooking particles, and their proportions in quantified organic matter does not exceed 2.07\% (Schauer et al., 2002; Zhao et al., $2007 \mathrm{a}, \mathrm{b})$. However, because the human body is often exposed to PAHs by direct inhalation into the lungs, the skin, or feeding, and some of the PAHs are carcinogenic, PAHs have received more attention.

One of the major sources of carbonyl compounds is the incomplete combustion of carbonaceous materials. In cooking activities, both combustion of fuel and heating of cooking oil produce carbonyl compounds. For example, different types of fuels, such as natural gas, liquefied petroleum gas, kerosene, and carbon, produce formaldehyde (gaseous) and acetaldehyde (Zhang et al., 1999). Some of these carbonyl compounds (such as formaldehyde, acetaldehyde, and acrolein) pose a threat to human health. Formaldehyde (gaseous), acetaldehyde, acrolein and pelargonic aldehyde are the most common carbonyl compounds produced during cooking (Schauer et al., 2002; Katragadda et al., 2010).

Fatty acids have been found to be a main component of cooking particles in all previous studies. Table 3 lists the proportion of fatty acids in quantified organics and the highest concentrations of saturated and unsaturated fatty acids in each test. The table shows that the proportion of fatty acids in quantified organics ranges from $73.4 \%$ to $95.7 \%$. During cooking, glycerides release free fatty acids by hydrolysis and thermal oxidation (Rogge et al., 1991). Particularly, vegetable fats contain more unsaturated fatty acids than animal fat.

Dicarboxylic acids come from the oxidative decomposition of dialdehydes during the auto-oxidation of unsaturated fats (Rogge et al., 1991; Schauer et al., 1999). In general, the concentration of dicarboxylic acid produced during cooking is one to two orders of magnitude lower than the

Table 2. The ratio of number of fine particles and total particles during cooking process.

\begin{tabular}{llll}
\hline Cooking style & Items & Amount ratio & References \\
\hline Laboratory kitchen (Pan-frying of beefsteak) & $\mathrm{PM}_{0.3-0.5} / \mathrm{PM}_{1}$ & $0.77-0.82$ & Sjaastad et al., 2008 \\
Laboratory kitchen (oil-heating) & $\mathrm{PM}_{0.01-0.1} / \mathrm{PM}_{0.01-0.5}$ & $0.76-0.99$ & Torkmahalleh et al., 2012 \\
Laboratory kitchen (oil-heating) & $\mathrm{PM}_{0.3} / \mathrm{PM}_{1}$ & $0.84-0.90$ & Zhao et al., 2019 \\
Laboratory kitchen (frying onion) & $\mathrm{PM}_{0.1} / \mathrm{PM}_{1}$ & $\sim 0.8$ & Glytsos et al., 2010 \\
Singapore commercial & $\mathrm{PM}_{0.1} / \mathrm{PM}_{10}$ & $>0.9$ & See et al., 2006 \\
American residential & $\mathrm{PM}_{0.1} / \mathrm{PM}_{10}$ & $\sim 0.9$ & Wallace et al., 2004 \\
\hline
\end{tabular}


Table 3. Summary of the test fatty acid.

\begin{tabular}{lllll}
\hline Cooking style & $\begin{array}{l}\text { Highest } \\
\text { concentration of } \\
\text { saturated fatty acids }\end{array}$ & $\begin{array}{l}\text { Highest concentration } \\
\text { of unsaturated fatty } \\
\text { acids }\end{array}$ & $\begin{array}{l}\text { Proportion of fatty } \\
\text { acids in the quantified } \\
\text { organic matter/\% }\end{array}$ & References \\
\hline Shanghai-style & Hexadecanoic acid & Linoleic acid & 90.9 & Pei et al., 2016 \\
Sichuan-style & Hexadecanoic acid & Oleic acid & 95.3 & \\
Italian-style & Hexadecanoic acid & Oleic acid & 93.2 & Zhao et al., 2007a \\
Guangdong-style & Hexadecanoic acid & Oleic acid & 75.5 & \\
Sichuan-style & Hexadecanoic acid & Oleic acid & 81.8 & \\
Dongbei-style & Hexadecanoic acid & Oleic acid & 73.4 & Zhao et al., 2015 \\
Hunan-style & Hexadecanoic acid & Oleic acid & 81.5 & He et al., 2004 \\
Chinese mixed cooking & Hexadecanoic acid & Linoleic acid & 75.7 & Zhao et al., 2007b \\
Hunan-style & Hexadecanoic acid & Linoleic acid & 95.7 & Schauer et al., 1999 \\
Guangdong-style & Hexadecanoic acid & Linoleic acid & 92.0 & 78.0 \\
Western fast food & Hexadecanoic acid & Oleic acid & 83.0 & \\
Barbecue-style & Hexadecanoic acid & Oleic acid & &
\end{tabular}

concentration of fatty acids (He et al., 2004; Zhao et al., 2007a, b; Zhao et al., 2015; Pei et al., 2016).

n-alkanes account for only a small fraction of cooking particles. According to previous studies, the proportion of $\mathrm{n}$-alkanes in quantified organics is $0.32-5.97 \%$ (Rogge et al., 1991; Oros et al., 2001a; Schauer et al., 2002; He et al., 2004; Zhao et al., 2007a, b; Zhao et al., 2015; Pei et al., 2016).

Cooking has an effect on the concentration of inorganic elements. There are many sources of metals from food additives, foods, edible oils and biomass burning (Anwar et al., 2004; Acciai et al., 2017; Zhao et al., 2019). For example, Kawashima et al. (2003) found $\mathrm{Cu}, \mathrm{Fe}, \mathrm{Mn}$, and $\mathrm{Zn}$ in vegetables, Lombardi-Boccia et al. (2004) found $\mathrm{Cu}$, $\mathrm{Fe}$, and $\mathrm{Zn}$ in meat, and Atta et al. (1997) found $\mathrm{Cu}, \mathrm{Zn}$, and $\mathrm{Cd}$ in fish. Mn could also be contained in the mushrooms. $\mathrm{Na}$ is likely derived from the salt used and $\mathrm{K}$ is associated with oil-based meat cooking and bio-related cooking (Tiner et al., 2013; Acciai et al., 2017). Certain elements, such as $\mathrm{Cr}, \mathrm{Fe}, \mathrm{Cu}$ and $\mathrm{Ni}$, may also come from cooking appliances (such as stainless-steel pans, and spatulas). Additionally, burning of fuel also releases inorganic elements. The toxins contained in heavy metals are absorbed onto the surface area of particles, which may cause heart and lung disease, inflammation or DNA damage (Senlin et al., 2008).

The main water-soluble ions in cooking particles are $\mathrm{Na}^{+}, \mathrm{NH}_{4}^{+}, \mathrm{SO}_{4}{ }^{2-}, \mathrm{NO}_{3}^{-}, \mathrm{K}^{+}, \mathrm{Ca}^{2+}$ and $\mathrm{Cl}^{-}$. Wang et al. (2015) research on commercial restaurants showed that water-soluble ions accounted for $9.1-17.5 \%$ of the total mass of $\mathrm{PM}_{2.5}$, with $\mathrm{Na}^{+}, \mathrm{SO}_{4}^{2-}, \mathrm{K}^{+}, \mathrm{Cl}^{-}$, and $\mathrm{Ca}^{2+}$ accounting for $62.9-85.7 \%$ of the total mass of water-soluble ions. In Schauer et al. (2002) study, the identified ions included $\mathrm{Na}^{+}, \mathrm{NH}_{4}^{+}, \mathrm{SO}_{4}{ }^{2-}, \mathrm{NO}_{3}^{-}, \mathrm{K}^{+}$, and $\mathrm{Cl}^{-}$. The proportion of $\mathrm{NO}_{3}^{-}$was approximately $2.2 \%$, the proportion of $\mathrm{Na}^{+}, \mathrm{NH}_{4}{ }^{+}$, and $\mathrm{SO}_{4}{ }^{2-}$ was approximately $1.0 \%$, and the proportion of $\mathrm{K}^{+}$ and $\mathrm{Cl}^{-}$was approximately $0.27 \%$. According to previous research, $\mathrm{SO}_{4}{ }^{2-}$ might come from drinking water used in cooking (PUB, 2007), $\mathrm{NO}_{3}^{-}$came from nitrogen oxides produced when fuel was burned, and $\mathrm{Na}^{+}$and $\mathrm{Cl}^{-}$might come from salt (Wang et al., 2015).

The molecular biomarkers produced by the cooking process include two types: sterols and monosaccharide anhydrides. Sterols mainly include cholesterol, campesterol, stigmasterol and $\beta$-sitosterol. Monosaccharide anhydrides mainly include galactan, mannan, and levoglucan. Sterols are widely found in plant and animal tissues. The vegetable lipid membranes are mainly composed of phytosterols, such as $\beta$-sitosterol, campesterol, and stigmasterol. Cholesterol is widely present in animal tissues, such as animal fat (Oros et $a l ., 2001 \mathrm{a}, \mathrm{b}$ ). The main products of cellulose decomposition are levoglucosan, galactan and mannan. Levoglucan is also considered a tracer for biofuel combustion (Radzi bin Abas et al., 2004).

\section{Health Risk Assessment Indicators}

The potential hazard of COFs depends on exposure, which is a function of the concentration and time. It can be evaluated by two risk evaluation indexes: excess lifetime cancer risk (ELCR) and hazard quotient (HQ). ELCR is used to evaluate the harm of carcinogens to the human body. A higher ELCR value indicates a greater risk of human cancer. The reference value for ELCR is E-6 (i.e., the ELCR value should not exceed E-6). HQ is used to evaluate the harm of noncarcinogenic effects of carbonyl compounds. A higher value of $\mathrm{HQ}$ is linked to greater damage to the human body. The reference value for HQ is 1.0 (i.e., the HQ value should not exceed 1.0). Their calculation method is as follows:

ELCR is calculated as follows (U.S. EPA, 1994):

$\mathrm{ELCR}=\mathrm{CDI} \times \mathrm{SF}$

where CDI is the level of chronic intake $\left(\mathrm{mg} \mathrm{kg}^{-1} \mathrm{~d}^{-1}\right)$ and $\mathrm{SF}$ is the cancer slope factor $\left(\mathrm{kg} \mathrm{d}^{-1} \mathrm{mg}^{-1}\right)$.

HQ is calculated as follows (BJC/OR-271, 1999):

$H Q=\frac{C D I}{R f D}$

where RfD is the contaminant reference dose $\left(\mathrm{mg} \mathrm{kg}^{-1} \mathrm{~d}^{-1}\right)$. In previous studies, it was fully demonstrated that COFs 
show great harm to the human body. In two residential kitchens of Hong Kong where town gas (Residence A) and liquefied petroleum gas (Residence B) were used as the fuels, the cooking emission samples were collected and evaluated for the carcinogenic risks on the chronic exposure to benzene, formaldehyde and acetaldehyde in housewives (Huang et al., 2011). The results showed that, in residence A, formaldehyde accounted for $68 \%$ of the lifetime cancer risk, while the value was close to $100 \%$ in residence $\mathrm{B}$. The occupational exposure to cooking emissions was evaluated by ELCR analysis (See et al., 2006) in three commercial kitchens. The ELCRs was estimated to be 1.07E-3, 1.21E-2 and 4.08E-3 in Indian, Malay and Chinese kitchens, respectively. In Turkey, Taner et al. (2013) collected PM from 14 restaurants that was fueled with charcoal. The total HQ for $\mathrm{PM}_{2.5}$ was 4.09 , and the total ELCR was 1.57E-4. In Singapore, the physical and chemical properties of a typical Chinese food stall using a gas stove were investigated (See and Balasubramanian, 2006). The assessed value of total ELCR and HQ was 1.11E-4 and 1.54, respectively. In Taipei, four night markets that have high visitor densities were studied by Zhao et al. (2011), and sixteen PAHs were analyzed. The excess ELCR of cooks in almost all typical food stalls in the night markets ranged from E-6 to E-4. A health risk assessment in five household kitchens in northern Taiwan was conducted by $\mathrm{Yu}$ et al. (2015). The ELCR resulting from 2-h daily exposure to PAHs in these sampling sites ranged from $2.46 \mathrm{E}-6$ to $1.40 \mathrm{E}-5$. Carcinogenic risks of PAHs and heavy metals generated during domestic Chinese cooking were assessed by Zhang et al. (2017). The risk of PAHs and heavy metals was 5.8E-6 and 2.7E-3, respectively, without kitchen ventilation. All the above values were high above the recommended acceptable limit of ELCR and HQ.

\section{FACTORS AFFECTING THE RELEASE OF COOKING PARTICLES}

Many factors such as fuel, edible oil, cooking temperature, cooking method and cooking style (Karimatu et al., 2013) could influence the concentration, chemical composition and diffusion of cooking particles. In actual cooking process, the coupling effects of sampling position, food consumption and ventilation conditions would also result in changes in the characteristics of cooking particles. In the following, analysis will be conducted for each influencing factor.

\section{Cooking Fuels}

Most fire-based cooking that increases human health risks is based on the combustion of different fuel types (Kima et al., 2011). Cooking fuel has a significant effect on the contribution of particles in environment (To and Yeung, 2011). Several fuels are used for cooking, including biomass fuel (e.g., charcoal or wood), kerosene, coal, liquefied petroleum gas (LPG), natural gas and electrical energy.

In developing countries, traditional solid fuels - e.g., wood, dung, coal or agricultural residues — are used quite frequently, especially in unvented or flueless stoves, leading to solid fuels becoming the largest source of indoor pollution
(WHO, 2010; Tiwari et al., 2015; Shahid et al., 2019). Currently, $50-75 \%$ of people in some areas of southern Africa and South America, as well as more than $75 \%$ of people in China, and nearby countries, use solid fuels for cooking. In rural areas in Mexico, Brauer et al. (1996) monitored 22 kitchens and found that the average $\mathrm{PM}_{2.5}$ in the kitchen using LPG for cooking was $69 \mu \mathrm{g} \mathrm{m}^{-3}$, which was much lower than that in the kitchen using biomass $\left(555 \mu \mathrm{g} \mathrm{m}^{-3}\right)$ for cooking. Siddiqui et al. (2009) investigated 44 and 51 kitchens using LPG and wood for cooking, respectively. The results showed that, in the kitchen using $\mathrm{LPG}$, the daily average concentration of $\mathrm{PM}_{2.5}\left(380 \mu \mathrm{g} \mathrm{m}^{-3}\right)$ was significantly lower than that using wood $\left(2740 \mu \mathrm{g} \mathrm{m}^{-3}\right)$. Li et al. (2016) compared 107 households that used coal for cooking in the urban area of China with households using gas or electricity for cooking. The results showed that much higher inhalation exposure levels and indoor concentrations were in the households using coal for fuel. Changing from coal to electricity or gas, wood to LGP, and biomass to LGP for cooking reduced the $\mathrm{PM}_{2.5}$ in kitchen by $40-70 \%, 86.1 \%$ and $87.6 \%$, respectively. Xu et al. (2018) observed a similar conclusion that households using electrical power for cooking and heating could at least reduce by half personal exposure to $\mathrm{PM}_{2.5}$ as compared to solid fuel.

The above studies further confirmed that using clean fuels like, gas and electricity could reduce the indoor air pollution significantly. However, cooking with electric toaster ovens and gas or electric stoves was still an important source of UFPs (Du et al., 2018). The estimated emission rate of UFPs in the neighborhood was approximately E+12 particles $\mathrm{min}^{-1}$, and the peak personal exposure typically exceeded $\mathrm{E}+5$ particles $\mathrm{cm}^{-3}$ (Wang et al., 2015). Gas cooking produced higher concentration of particles than electric cooking. The study of 393 kitchen workers from 53 Chinese restaurants indicated (Wong et al., 2011) that, compared with electricity-fueled kitchens, gas-powered kitchens had a higher prevalence of respiratory symptoms and poorer lung function among the workers. Regarding the two relatively clean fuels that are commonly used in Hong Kong, electricity and town gas, the measurement results showed that, in domestic kitchens, electric cooking produced lower concentrations of $\mathrm{PM}_{10}$ than gas cooking for deep frying, stir frying and pan frying (To and Yeung, 2011). Zhang et al. (2010) observed a similar conclusion. When frying chips, the TSPs produced by cooking with natural gas was $118 \mu \mathrm{g} \mathrm{m}^{-3}$, while the electric cooking produced TSPs of only $27 \mu \mathrm{g} \mathrm{m}^{-3}$ (Buonanno et al., 2009). The concentration of the particle emissions from different cooking fuels is shown in Table 4.

Principal component analysis indicates that the main sources of indoor PAHs are combustion emissions from biomass, coal, diesel and gasoline. The 2-ring and some 3and 4-ring PAHs were mainly produced indoors due to cooking activities (Li et al., 2017). The samples of indoor burning of bio-fuels, such as corn cobs, from 8 sampling sites across the Beijing-Tianjin-Hebei region were dominated by 2, 3-ring PAHs (Li et al., 2018). Incomplete combustion of carbon-based fuels is also a major source of aldehydes. Zhang et al. (1999) measured a discharge coefficient of 
Table 4. Summary of the concentrations of particle emissions from different cooking fuels.

\begin{tabular}{|c|c|c|c|c|}
\hline Cooking style & Fuel & $\begin{array}{l}\text { Particle } \\
\text { size }\end{array}$ & $\begin{array}{l}\text { Concentration } \\
\left(\mu \mathrm{g} \mathrm{m}^{-3}\right)\end{array}$ & References \\
\hline Chinese commercial & \multirow[t]{10}{*}{ Gas } & \multirow[t]{7}{*}{$\mathrm{PM}_{2.5}$} & $404.8-494.9$ & Wang et al., 2015 \\
\hline Chinese residential & & & $65-184$ & Li et al., 2016 \\
\hline Chinese residential & & & $4-2731$ & Lu et al., 2019 \\
\hline Chinese residential & & & 160 & Wan et al., 2011 \\
\hline Singapore residential (Chinese style) & & & $65.7-190$ & See and Balasubramanian, 2008 \\
\hline American residential & & & $12.4-98.1$ & Zhang et al., 2010 \\
\hline Japan residential & & & $22.3-101.6$ & Huboyo et al., 2011 \\
\hline Chinese commercial & & $\mathrm{PM}_{10}$ & $890-4720$ & To and Yeung, 2011 \\
\hline Chinese residential & & TSPs & 138 & Zhao et al., 2015 \\
\hline Italy laboratory & & & $60-398$ & Buonanno et al., 2009 \\
\hline Indian residential & \multirow[t]{9}{*}{ Electricity } & \multirow[t]{6}{*}{$\mathrm{PM}_{2.5}$} & $34.5-143.7$ & Zhang et al., 2010 \\
\hline Chinese residential & & & 230.9 & \\
\hline Italian residential & & & 36.5 & \\
\hline American student dorm & & & $20.4-78.3$ & \\
\hline American residential & & & $10.0-22.2$ & \\
\hline Chinese residential & & & $55-153$ & Li et al., 2016 \\
\hline Chinese residential & & $\mathrm{PM}_{10}$ & $520-3980$ & To and Yeung, 2011 \\
\hline Italy laboratory & & TSPs & $12-27$ & Buonanno et al., 2009 \\
\hline Italy laboratory & & & $1000-11600$ & Sjaastad et al., 2008 \\
\hline Singapore commercial & Liquefied & $\mathrm{PM}_{2.5}$ & $201.8-312.4$ & See et al., 2006 \\
\hline Chinese commercial & \multirow[t]{2}{*}{ petroleum gas } & $\mathrm{PM}_{2.5}$ & 331.3 & Wang et al., 2015 \\
\hline \multirow{2}{*}{ African residential } & & $\mathrm{PM}_{2.5}$ & 328 & Giwa et al., 2019 \\
\hline & kerosene & $\mathrm{PM}_{2.5}$ & 345 & \\
\hline Chinese commercial & Charcoal & $\mathrm{PM}_{2.5}$ & 1841.9 & Wang et al., 2015 \\
\hline Chinese residential & Coal & $\mathrm{PM}_{2.5}$ & $107-213$ & Li et al., 2016 \\
\hline Chinese residential & Yak dung & $\mathrm{PM}_{2.5}$ & $56.6-1280$ & Xiao et al., 2015 \\
\hline Chinese residential & $\begin{array}{l}\text { Wood or crop } \\
\text { residues }\end{array}$ & $\mathrm{PM}_{2.5}$ & $111 \pm 63$ & Qi et al., 2018 \\
\hline Chinese residential & Wood or coal & $\mathrm{PM}_{2.5}$ & $310.8 \pm 90.4$ & Xu et al., 2018 \\
\hline \multirow{2}{*}{ Western commercial } & Wood & $\mathrm{PM}_{2.5}$ & $12-369$ & Buonanno et al., 2010 \\
\hline & & $\mathrm{PM}_{10}$ & $15-482$ & \\
\hline
\end{tabular}

aldehyde materials in common cooking fuels. The results showed that all the carbon-based cook stoves produced aldehydes. LPG and kerosene stoves generated fewer carbonyl compounds than biomass stoves but more than coal gas, coal and natural gas stoves.

\section{Edible Oil}

The composition and emission of cooking fumes are also related to edible oil. Various edible oils used in cooking are closely connected to people's eating habits. When the type of edible oil is modified, thermal cracking products are different. Researchers have conducted extensive studies on the smoke point and volatile products emitted from cooking with different edible oils. During frying with margarine, significantly higher particle numbers in all size fractions are observed than frying with rapeseed, soybean and olive oils (Sjaastad et al., 2008). In Chiang et al. (1999) study, the amount of cooking particles was higher (but not significant) in vegetable oil than sunflower and refined-lard oils. The emission factors determined in Buonanno et al. (2009) study revealed the following order of emissions: olive oil $\left(118 \mathrm{mg} \mathrm{m}^{-3}\right)>$ peanut oil $\left(68 \mathrm{mg} \mathrm{m}^{-3}\right)>$ sunflower oil $\left(60 \mathrm{mg} \mathrm{m}^{-3}\right)$. This is consistent with the conclusions of
Torkmahalleh et al. (2012) that olive, corn oils and coconut generated higher $\mathrm{PM}_{2.5}$ concentrations than peanut, safflower, soybean and canola oils. At the highest monitored temperature $\left(197^{\circ} \mathrm{C}\right)$, the $\mathrm{PM}_{2.5}$ concentration during cooking olive oil is approximately 10 fold higher than that of safflower oil. Differences in the composition of the oils will affect their fume temperature. The semivolatile compounds emitted from oil condense and form an aerosol phase; consequently, the particle emissions occur (Buonanno et al., 2011). Therefore, the composition of the oil further affects the particle emission rate (Torkmahalleh et al., 2012). For example, soybean oil, safflower oil, canola oil and peanut oil are known to be quite low-particle emitters compared with corn, coconut and olive oils due to the higher smoke point temperature.

The impact of oil choice on carbonyl emissions for barbecue and stir-frying cooking was investigated by Xiang et al. (2017). Generally, carbonyl emissions produced from soybean oil were higher than from corn oil. The significantly high amount of carbonyls was possibly due to the presence of large amounts of water in materials. The types of edible oil may affect the generation of aldehydes. According to the results of previous studies, acetaldehyde 
and amyl aldehyde can be obtained from linoleic acid, hexanal, 2-heptene aldehyde, 2-octene aldehyde, 2-nonene aldehyde and 2, 4-sebacic olefin aldehyde. Therefore, if cooking oil contains linoleic acid, it is easier to produce more oleic acid decomposition, which can produce caprylic aldehyde, nonyl aldehyde, decanal, and 2-decyl olefin aldehyde (Subramanian and Nakajima, 1997). Katragadda et al. (2010) confirmed the same conclusion. They measured the aldehyde-producing conditions of 4 kinds of cooking oil. The content of linoleic acid among the four kinds of cooking oil was in the following order, from highest to lowest: safflower oil, canola oil, olive oil and coconut oil. The results showed that 2-heptene aldehyde substances produced by safflower oil was far more abundant than the other three kinds of edible oil. However, the emission rates of decyl olefin aldehyde and nonyl aldehyde in olive oil were higher than those of other cooking oils. In addition, the type of cooking oil will also affect the distribution of fatty acids. Schauer et al. (2002) found that the distribution of $\mathrm{C} 18$ fatty acids (including stearic, oleic, linoleic and linolenic acids) in the cooking particles was consistent with the distribution in edible oils. In their tests, the highest proportion of oleic acid was found in canola oil. Canola oil cooking also produced a large amount of oleic acid. The results showed that all cooking oils produced only a very small amount of linolenic acid.

\section{Cooking Temperature}

Many particles are generated during high-temperature cooking process. A high cooking temperature increases the particle number, mass concentration, mode diameter (geometric mean diameter) and emission factor. In Buonanno et al. (2009), an increase of 29-fold in the case of mass concentration and a $70 \%$ increase in the number concentration can be observed with an elevated cooking temperature. However, the influence of oil temperature on emission rates of $\mathrm{PM}_{2.5}$ and UFPs was not significant in the experiment conducted by Zhao et al. (2018), because practical peak oil temperatures $\left(112-177^{\circ} \mathrm{C}\right)$ were mostly below the oil smoke point $\left(107-234^{\circ} \mathrm{C}\right)$. Temperature is also found to have a significant impact on the mode diameter. At high temperature, the particles intercoagulate easily and, eventually, the diameter mode of particles increased. This effect was also observed by Yeung and To (2008). When the cooking temperature changed from $200^{\circ} \mathrm{C}$ to $220^{\circ} \mathrm{C}$ during frying chicken, the mode diameter of the particles increased from $103 \mathrm{~nm}$ to $160 \mathrm{~nm}$. A similar situation occurred in the process of frying steaks and pork chops. Yeung and To (2008) also drew a conclusion that the size distribution of particles followed a lognormal distribution. However, some researchers found that the particle size appeared to show a bimodal distribution based on particle number (Glytsos et al., 2010; Torkmahalleh et al., 2012). When cooking temperature was low, the bimodal distribution was nonexistent. At a high cooking temperature, the smaller sized particles could condense into a larger size, leading to a size distribution of particles followed by a lognormal distribution or bimodal distribution based on the particle number. It was also observed that the particle emission factor is a function of the increased cooking temperature. When the carbon combustion temperature rose from $450^{\circ} \mathrm{C}$ to $550^{\circ} \mathrm{C}$, the released $\mathrm{PM}_{2.5}$ increased from $19.8 \mathrm{mg} \mathrm{kg}^{-1}$ to $241.3 \mathrm{mg} \mathrm{kg}^{-1}$. The total $\mathrm{PM}_{10}$ emissions increased from $31.1 \mathrm{mg} \mathrm{kg}^{-1}$ to $292.8 \mathrm{mg} \mathrm{kg}^{-1}$ (Huang et al., 2016).

With the rising temperature, the emissions of most PAHs, aldehydes, inorganic and unsaturated fatty acids pyrolysis increase. Chiang et al. (1999) indicated that PAHs were mainly formed by unsaturated fatty acids, which were oxidized at high temperature. Most PAHs increase with temperature. BaP showed a notable increase, while Acl rapidly increased. Besides, some 3-ring PAHs, such as PHEN, hardly increase at elevated temperatures (Zhu and Wang, 2003; Hao et al., 2016). Katragadda et al. (2010) found that, during the heating process, the generation rate of aldehydes increased with the oil temperature. When the oil temperature exceeds the smoke point, the generation rate of aldehydes increased dramatically. With safflower oil (smoke point $217 \pm 2^{\circ} \mathrm{C}$ ), when the oil temperature increased from $210^{\circ} \mathrm{C}$ to $240^{\circ} \mathrm{C}$, the generation rate of aldehydes increased to $1971 \mathrm{mg} \mathrm{h}^{-1} \mathrm{~L}^{-3}$. Additionally, high cooking temperatures would lead to a higher concentration of inorganic elements. Therefore, high-temperature cooking should be avoided. In cooking process, oil temperature should not be higher than the smoke point.

\section{Cooking Method}

Cooking method has been known as one of the important factors affecting the emission of some essential pollutants (Abdullahi et al., 2013). Current research has shown that heavy-load cooking method, such as deepfrying, barbecue (pan-frying), and stir-frying produces more PM, PAHs and inorganic elements than others.

The $\mathrm{PM}_{2.5}$ mass concentration determined in See and Balasubramanian (2008) study revealed the following order of emissions: deep frying $\left(209 \mu \mathrm{g} \mathrm{\textrm {m } ^ { - 3 }}\right)>$ pan frying $\left(130 \mu \mathrm{g} \mathrm{m}^{-3}\right)>$ stir frying $\left(120 \mu \mathrm{g} \mathrm{m}^{-3}\right)>$ boiling $\left(91.6 \mu \mathrm{g} \mathrm{m}^{-3}\right)$ $>$ steaming $\left(72.3 \mu \mathrm{g} \mathrm{m}^{-3}\right)>$ background $\left(15.4 \mu \mathrm{g} \mathrm{m}^{-3}\right)$. The observation also agrees with the research results reported by Lee et al. (2001), Wang et al. (2015), Giwa et al. (2019) and $\mathrm{Lu}$ et al. (2019). Wang et al. (2015) conducted a measurement of $\mathrm{PM}_{2.5}$ emitted from different cooking styles, mainly including mixed cooking, stir frying (in home, Shandong cuisine restaurants and Hunan cuisine restaurants) and barbecue. They found that barbecue (pan frying) restaurants had the highest $\mathrm{PM}_{2.5}$ concentration, 3.7 to 5.6 times higher than others. The observation was consistent with McDonald et al. (2003) who reported that charbroiling produced higher concentrations of PM than stir frying. Lee (2001) found the $\mathrm{PM}_{2.5}$ concentration was the highest in Korean barbecue restaurants (pan frying), following by Chinese hot pot restaurants (boiling) and Chinese dim sum restaurants (steaming). The same conclusion was also made by See et al. (2006) who compared the $\mathrm{PM}_{2.5}$ emitted from three commercial kitchens with different cooking methods (Indian (boiling), Chinese (stir frying), and Malay (deep frying)). In three residence measurements conducted by Zhang et al. (2010), it was also found that, during 
boiling, lower UFPs concentrations were observed, while the UFPs levels were higher during frying. Many researches have reported similar results (Rogge et al., 1991; Buonanno et al., 2010; Taner et al., 2013; Sofuoglu et al., 2015). A summary of the particle concentrations generated from different cooking methods are presented in Table 5. The concentrations of PM varied considerably, even with the same cooking method, indicating the sensitivity of the measurement conditions where small details and measurement location can have a significant effect on the results.

Saito et al. (2014) found that, regardless of cooking method and food material, the main components of PAHs were 3- and 4-ring PAHs. Naphthalene (Nap) was the most abundant PAHs among the total measured gaseous PAHs (Wang et al., 2015; Hao et al., 2016). The emission rates of Nap were the highest for oil based cooking methods, while Phenanthrene (Phe) and Chrysene (Chr) emissions were the highest for steaming and boiling (Zhao et al., 2019). It is believed during deep frying, the mass concentration of PAHs was the highest, followed by pan frying, stir frying, boiling and steaming (Lee et al., 2001; See and Balasubramanian, 2006, 2008; Wang et al., 2015). However, Zhao et al. (2019) found out the concentrations of 16 PAHs in $\mathrm{PM}_{2.5}$ followed by stir-frying (58.90-92.14 $\mathrm{ng} \mathrm{m}^{-3}$ ), pan-frying (41.23$72.57 \mathrm{ng} \mathrm{m}^{-3}$ ), deep-frying (34.57-50.89 $\mathrm{ng} \mathrm{m}^{-3}$ ), steaming $\left(29.54 \mathrm{ng} \mathrm{m}^{-3}\right)$, and boiling $\left(8.00 \mathrm{ng} \mathrm{m}^{-3}\right)$. During deep frying using edible oils, the levels of PAHs, especially the heavier PAHs (5-ring or above), are increased. The mean concentration of high-ring PAHs (5-ring or above) for deep-frying oils for 45 min was 31.5 times higher than the levels for fresh oils (Hao et al., 2016). During water based cooking or mixed cooking, high-ring (5-ring or above) PAHs were the most abundant compared with oil-based cooking (Zhu and Wang, 2003; Zhao et al., 2019). The most common PAHs with carcinogenic effects are the fourto six-ring compounds. This indicated that lower cooking temperature and less cooking oil consumption does not mean the steaming and boiling processes are less harmful. This is the reason why Chinese-style hot pot restaurant (boiling-based) emitted nearly the same amount of pollutants as barbecue restaurant (Lee et al., 2001). The emission of those two cooking processes all exceed the limits of cancer risk (10 E-6) and the hazard index (=1) (Ho et al., 2006;
Cheng et al., 2016).

According to the experiment conducted by Xiang et al. (2017), the carbonyls (C1-C8) emission factors were in the following order: barbecue $\left(1.596 \mu \mathrm{g} \mathrm{kg}^{-1}\right)>$ frying $\left(1.530 \mu \mathrm{g} \mathrm{kg}^{-1}\right)>$ teppanyaki $\left(1.229 \mu \mathrm{g} \mathrm{kg}^{-1}\right)>$ stir-frying $\left(0.699 \mu \mathrm{g} \mathrm{kg}^{-1}\right)$, while $\mathrm{C} 1-\mathrm{C} 3$ carbonyls accounted for over $85 \%$ for all cooking types. The primary pollutant produced from cooking was formaldehyde, followed by acetaldehyde and acetone. Barbecue produced higher amount of acetaldehyde and propanal than other carbonyls. Formaldehyde produced from stir-frying was very high while the acetaldehyde produced was negligible.

Regardless of cooking method, $\mathrm{Ca}, \mathrm{Na}, \mathrm{Fe}, \mathrm{K}, \mathrm{Al}, \mathrm{Mg}$ and $\mathrm{S}$ are the most abundant elements in the cooking profiles and their mass fractions account for approximately $98 \%$ of the measured elements (See and Balasubramanian, 2008; Li, et al., 2015; Wang, et al., 2015; Zhang et al., 2017; Zhao et al., 2019). The concentrations of inorganic elements generated from different cooking methods followed the same order of PM and oil-based cooking generated more elements than water-based cooking (See and Balasubramanian, 2008; Zhao et al., 2019). With the same inorganic elements, ions of cooking particles are also affected by the cooking method. The concentrations of ions emitted during steaming and boiling were higher than those emitted during stir frying even with the same cooking temperature and cooking oil consumption. This might be related to tap water being rich in $\mathrm{Cl}^{-}, \mathrm{F}^{-}$and $\mathrm{SO}_{4}{ }^{2-}$ concentrations. The concentrations of $\mathrm{Cl}^{-}, \mathrm{F}^{-}$and $\mathrm{SO}_{4}{ }^{2-}$ in tap water varied in the ranges of 5-100 ppm, 0.4-0.6 ppm and 5-60 ppm, respectively. However, the concentrations of the three ions in cooking oils were only $1-6.5 \mathrm{ppm}, 1 \mathrm{ppm}$ and 1 ppm, respectively (Dugo et al., 2007). Therefore, the water-based cooking method releases a large amount of $\mathrm{Cl}^{-}, \mathrm{F}^{-}$, and $\mathrm{SO}_{4}{ }^{2-}$ compared with the oil-based cooking method, likely explaining the ion concentration in the following order: boiling $>$ steaming $>$ stir frying in the test of See and Balasubramanian (2008).

\section{Chinese and Western Cooking Styles}

Chinese cuisine emphasizes a balanced diet, mainly vegetables, and the ingredients are reasonable, while Western foods have a higher proportion of fat and meat

Table 5. Summary of the concentrations of particle emissions from different cooking methods.

\begin{tabular}{|c|c|c|c|c|c|}
\hline Cooking style & Features & $\begin{array}{l}\text { Particle } \\
\text { size }\end{array}$ & $\begin{array}{l}\text { Concentration } \\
\left(\mu \mathrm{g} \mathrm{m}^{-3}\right)\end{array}$ & Sampling points & References \\
\hline \multirow{9}{*}{$\begin{array}{l}\text { Chinese style } \\
\text { (commercial) }\end{array}$} & Mixed cooking & $\mathrm{PM}_{2.5}$ & $331.3-494.9$ & Rooftop exhaust & Wang et al., 2015 \\
\hline & Barbecue & $\mathrm{PM}_{2.5}$ & 1841.9 & & \\
\hline & Mixed cooking & $\mathrm{PM}_{2.5}$ & $471-693$ & Rooftop exhaust & Pei et al., 2016 \\
\hline & Deep-frying & $\mathrm{PM}_{2.5}$ & $76-158$ & $1.5 \mathrm{~m}$ above the ground near & Sofuoglu et al., \\
\hline & & $\mathrm{PM}_{10}$ & $279-1583$ & (50 $\mathrm{cm}$ away) the deep-fryer & 2015 \\
\hline & Deep frying & $\mathrm{PM}_{10}$ & $3980-4720$ & $0.2 \mathrm{~m}$ from the center of & To and Yeung, \\
\hline & Griddle frying & $\mathrm{PM}_{10}$ & $2260-2600$ & cooking device and $1.0 \mathrm{~m}$ & 2011 \\
\hline & Broiling & $\mathrm{PM}_{10}$ & $\begin{array}{l}\text { Out of range } \\
(E+5)\end{array}$ & above the cooking surface & \\
\hline & Mixed cooking & $\mathrm{PM}_{2.5}$ & 312.4 & $\begin{array}{l}\text { Near the stove and } 1.5 \mathrm{~m} \\
\text { above the ground }\end{array}$ & See et al., 2006 \\
\hline
\end{tabular}


Table 5. (continued).

\begin{tabular}{|c|c|c|c|c|c|}
\hline Cooking style & Features & $\begin{array}{l}\text { Particle } \\
\text { size }\end{array}$ & $\begin{array}{l}\text { Concentration } \\
\left(\mu \mathrm{g} \mathrm{m}^{-3}\right)\end{array}$ & Sampling points & References \\
\hline \multirow{19}{*}{$\begin{array}{l}\text { Chinese style } \\
\text { (residential) }\end{array}$} & Mixed cooking & TSP & 138 & Rooftop exhaust & Zhao et al., 2015 \\
\hline & Mixed cooking & $\mathrm{PM}_{2.5}$ & $55-213$ & Breathing zone $(1.0-1.5 \mathrm{~m})$ & Li et al., 2016 \\
\hline & Mixed cooking & $\mathrm{PM}_{2.5}$ & $56.6-1280$ & $\begin{array}{l}0.5 \mathrm{~m} \text { above the ground and } \\
1 \mathrm{~m} \text { horizontally away from } \\
\text { the stove }\end{array}$ & Xiao et al., 2015 \\
\hline & Mixed cooking & $\mathrm{PM}_{2.5}$ & 160 & $1.7 \mathrm{~m}$ above the floor & Wan et al., 2011 \\
\hline & Frying & $\mathrm{PM}_{2.5}$ & 230.9 & $\begin{array}{l}\text { Breathing zone and } 1 \mathrm{~m} \text { from } \\
\text { the stove }\end{array}$ & Zhang et al., 2010 \\
\hline & Steaming & $\mathrm{PM}_{2.5}$ & 65.7 & $0.2 \mathrm{~m}$ from the burner and & See and \\
\hline & Boiling & $\mathrm{PM}_{2.5}$ & 81.4 & $1.5 \mathrm{~m}$ above the ground & Balasubramanian, \\
\hline & Stir-frying & $\mathrm{PM}_{2.5}$ & 120 & & 2008 \\
\hline & Pan-frying & $\mathrm{PM}_{2.5}$ & 130 & & \\
\hline & Deep-frying & $\mathrm{PM}_{2.5}$ & 190 & & \\
\hline & Steaming & $\mathrm{PM}_{2.5}$ & $11-88$ & Breathing zone and $1.4 \mathrm{~m}$ & Lu et al., 2019 \\
\hline & Boiling & $\mathrm{PM}_{2.5}$ & $4-247$ & above the ground & \\
\hline & Quick-frying & $\mathrm{PM}_{2.5}$ & $140-433$ & & \\
\hline & Stewing & $\mathrm{PM}_{2.5}$ & $0-573$ & & \\
\hline & Stir-frying & $\mathrm{PM}_{2.5}$ & $700-598$ & & \\
\hline & Deep-frying & $\mathrm{PM}_{2.5}$ & $709-2731$ & & \\
\hline & Frying & $\mathrm{PM}_{10}$ & $1030-1330$ & $0.2 \mathrm{~m}$ from the center of & To and Yeung, \\
\hline & Pan frying & $\mathrm{PM}_{10}$ & $520-1020$ & cooking device and $1.0 \mathrm{~m}$ & 2011 \\
\hline & Deep frying & $\mathrm{PM}_{10}$ & $680-890$ & above the cooking surface & \\
\hline \multirow{8}{*}{$\begin{array}{l}\text { Western style } \\
\text { (commercial) }\end{array}$} & Mixed cooking & $\mathrm{PM}_{2.5}$ & 502 & Rooftop exhaust & Pei et al., 2016 \\
\hline & Mixed cooking & $\mathrm{PM}_{2.5}$ & 245.3 & $\begin{array}{l}\text { Near the stove and } 1.5 \mathrm{~m} \\
\text { above the ground }\end{array}$ & See et al., 2006 \\
\hline & Grilling & TSP & $78-389$ & $2 \mathrm{~m}$ from the stove & Buonanno et al., \\
\hline & Frying & TSP & $12-118$ & & 2009 \\
\hline & Pan-frying & TSP & $1000-11600$ & $\begin{array}{l}\text { Placed on the left shoulder of } \\
\text { the chef }\end{array}$ & $\begin{array}{l}\text { Sjaastad et al., } \\
2008\end{array}$ \\
\hline & Baking & $\mathrm{PM}_{1}$ & $10-327$ & In the center of the & Buonanno et al., \\
\hline & & $\mathrm{PM}_{2.5}$ & $12-369$ & restaurants & 2010 \\
\hline & & $\mathrm{PM}_{10}$ & $15-482$ & & \\
\hline $\begin{array}{l}\text { Western style } \\
\text { (residential) }\end{array}$ & Frying & $\mathrm{PM}_{2.5}$ & $10.0-98.1$ & $\begin{array}{l}\text { Breathing zone and } 1 \mathrm{~m} \text { from } \\
\text { the stove }\end{array}$ & Zhang et al., 2010 \\
\hline $\begin{array}{l}\text { Other Asian style } \\
\text { (commercial) }\end{array}$ & Mixed cooking & $\mathrm{PM}_{2.5}$ & 201.8 & $\begin{array}{l}\text { Near the stove and } 1.5 \mathrm{~m} \\
\text { above the ground }\end{array}$ & See et al., 2006 \\
\hline \multirow{4}{*}{$\begin{array}{l}\text { Other Asian style } \\
\text { (residential) }\end{array}$} & Pan-frying & $\mathrm{PM}_{2.5}$ & $34.5-143.7$ & Breathing zone and $1 \mathrm{~m}$ from & Zhang et al., 2010 \\
\hline & $\begin{array}{l}\text { Boiling and stir- } \\
\text { frying }\end{array}$ & $\mathrm{PM}_{2.5}$ & 36.5 & the stove & \\
\hline & Boiling & $\mathrm{PM}_{2.5}$ & $22.3-30.9$ & Near the stove and $1.1 \mathrm{~m}$ & Huboyo et al., \\
\hline & Frying & $\mathrm{PM}_{2.5}$ & $41.1-101.6$ & above the floor & 2011 \\
\hline
\end{tabular}

TSP: total suspended particle.

Mixed cooking: many cooking techniques are used at the same time.

Barbecue: encompasses four or five distinct types of cooking techniques, like smoking, baking, braising and grilling.

Baking: a method of cooking food that uses prolonged dry heat, normally in an oven, but also in hot ashes, or on hot stones.

Frying: the cooking of food in oil or another fat.

Deep-frying: a cooking method in which food is submerged in hot fat, most commonly oil, rather than the shallow oil used in conventional frying, done in a frying pan.

Stir-frying: a Chinese cooking technique in which ingredients are fried in a small amount of very hot oil while being stirred in a wok.

Pan-frying: a form of frying characterized by the use of minimal cooking oil or fat (compared to shallow frying or deep frying); typically using just enough oil to lubricate the pan.

Grilling: a form of cooking that involves dry heat applied to the surface of food, commonly from above or below.

Steaming: a method of cooking using steam.

Boiling: the method of cooking food in boiling water, or other water-based liquids such as stock or milk. 
than vegetables. It is generally believed that Asian-style cooking emits more PM than Western cooking (Lee et al., 2001; Levy et al., 2002; He et al., 2004). For example, grilling Chinese-style food could elevate the concentrations of $\mathrm{PM}_{2.5}$ and submicron particles up to 90 and 5 times higher than European-style cooking, respectively (He et al., 2004). Compared with low-fat vegetables, the particle emission factor of high-fat food is much higher. Additionally, the particle size of a high-fat diet may be larger than that of low-fat food even under the same cooking conditions (Torkmahalleh et al., 2013). However, the study concluded by Wang et al. (2018) found that the particle concentration released from non-meat ingredients was significantly higher than those from meat, and the decay rate of the particle concentration of cooking meat was significantly lower than that of cooking nonmeat.

The PAHs, nonyl aldehyde, fatty acid, dicarboxylic acid and n-alkanes released during the cooking process in Chinese and Western cooking processes are also quite different. Previous studies have shown a similar distribution of PAH components from different cooking cuisines in Guangzhou China. Its main components were naphthalene, phenanthrene, fluoranthene, pyrene and fluorene, constituting $77.1 \%-84.1 \%$ of the total quantified PAHs (Zhao et al., 2015). Many studies have indicated that pyrene was the highest in typical Chinese cooking emissions (He et al., 2004; Zhao et al., 2007a). However, chrysene contributed to the highest mass fraction in seed oil cooking and meat cooking (Rogge et al., 1991; Schauer et al., 1999, 2002) and the phenanthrene concentration was the highest in beef or chicken grilling and charbroiling (McDonald et al., 2003). More 5-ring PAHs than other PAHs were found in restaurant cooking in Hong Kong ( $\mathrm{Hu}$ et al., 2012). It should be noted that the mass concentrations of benzo[a]pyrene in Chinese restaurant emissions were always above the threshold value according to the 2nd-level air quality in China (GB 3095-2012). This may be related to the very hot oil and strong stirring in a wok during the Chinese cooking process, leading to a high incidence of lung cancer in Chinese women who smoke little (Zhao et al., 2007b; Zhao et al., 2015; Pei et al., 2016). Different from Chinese style cooking, benzo $(b+k)$ fluorescein was the main $\mathrm{PAH}$ compound found in Western-style fast food cooking, and fluorene was the main PAH emitted from the Western style restaurants (Zhao et al., 2007b; Pei et al., 2016).

Generally, Carbonyl emissions from non-meat dishes were smaller than for meat dishes (Xiang et al., 2017). In Chinese-style and Western-style cooking, the aldehyde concentration was approximately the same as the distribution of carbon atoms. Only nonyl aldehyde showed an obvious difference: the nonyl aldehyde concentration in Western cooking was an order of magnitude higher than that in Chinese cooking (Schauer et al., 2002; Ho et al., 2006; Zhao et al., 2007b; Cheng et al., 2016). Nonyl aldehyde is from the decomposition of oleic acid (a fatty acid produced by cooking oil) (Schauer et al., 2002). Compared with Chinese-style cooking, Western cooking uses more cooking oil. This may be one of the reasons for the high concentration of nonyl aldehyde in Western cooking. Other researches also support this explanation. In the field test study in 15 restaurants, Western-style fast food restaurants had the highest concentration of nonyl aldehydes (Ho et al., 2006).

Fatty acids were found to be the most important constituents of cooking particles. Western-style cooking processes produce a higher concentration of fatty acids than Chinese cooking. Pei et al. (2016) analyzed the emissions from three restaurants. They found that the total concentration of fatty acids in Italian restaurant cooking was 2-3 times higher than that of Shanghai restaurant and Sichuan restaurant. Zhao et al. (2007b) measured a Westernstyle fast food restaurant and compared the results with Chinese-style cooking. It was found that the fatty acids in fast food restaurants was 13 times higher than in Chinese restaurant. Similar to the results of Zhao et al., (2015), the total concentration of the fatty acids in Western-style fast food restaurants was approximately 10 times higher than that in Chinese-style cooking. Higher fatty acid concentrations in Western cooking are associated with a greater use of highfat food ingredients and high cooking temperature. Highfat foods release more fatty acids during the cooking process than lower-fat foods, and high cooking temperatures make grease and vegetable fat more easily release free fatty acids. Chinese cooking has a higher proportion of unsaturated fatty acids than Western cooking. In Chinese cooking, the ratio of unsaturated fatty acids and saturated fatty acids was generally 1.2-4.4 and that in Western cooking was only 0.3-1.1 (He et al., 2004; Zhao et al., 2007b; Pei et al., 2016). In both Western and Chinese cooking, the highest concentration of saturated fatty acids was palmitic acid, while the highest level of unsaturated fatty acids in Western and Chinese cooking were oleic acid and oleic acid or linoleic acid, respectively.

Regarding dicarboxylic acids, Western cooking and Chinese cooking have two major differences: the mass concentration and composition. Zhao et al. (2007b) found that the mass concentration of dicarboxylic acid in Westernstyle cooking was almost 30 times higher than that in Chinese-style cooking. Western cooking with high cooking temperature resulted in a large number of unsaturated fatty acid pyrolysis, explaining the high concentration of dicarboxylic acid. Another reason is the higher consumption of meat than in Chinese cooking. Regarding the composition, the main components of dicarboxylic acid in Chinese cooking was azelaic acid. In Western-style cooking, adipic acid, octyl diacid and azelaic acid were the most common components (Table 6). In addition, the ratio between adipic acid and azelaic acid in Western cooking was greater than 1, while the ratio was less than 1 in Chinese cooking (Zhao et al., 2007b).

The proportion of n-alkanes in the quantified organic compounds was $0.32-5.97 \%$. There were three main differences in cooking particles between Chinese and Western cooking. First, C29 and C31 were generally of the highest concentration in n-alkanes produced in Chinese cooking. This reflected the high proportion of vegetables used in Chinese cooking (Simoneit et al., 1986; Rogge et al., 1993). In Western cooking, the concentration of $\mathrm{C} 25$ was generally the highest, while the process of cooking 
Table 6. Summary of the test dicarboxylic acid.

\begin{tabular}{llll}
\hline Cooking style & Dicarboxylic acid ingredient & $\begin{array}{l}\text { Main component proportion } \\
\text { in the dicarboxylic acid/\% }\end{array}$ & References \\
\hline Shanghai-style & Azelaic acid & 55.1 & Pei et al., 2016 \\
Sichuan-style & Azelaic acid & 58.3 & Zhao et al., 2007a \\
Italian-style & Azelaic acid, Suberic acid & 76.3 & \\
Guangdong-style & Azelaic acid & 63.1 & Zhao et al., 2015 \\
Sichuan-style & Azelaic acid & 58.3 & He et al., 2004 \\
Dongbei-style & Azelaic acid & 49.5 & Zhao et al., 2007b \\
Hunan-style & Azelaic acid & 54.8 & Schauer et al., 1999 \\
Chinese mixed cooking & Azelaic acid & 50.8 & 58.1 \\
Hunan-style & Azelaic acid & 87.1 & 100.0 \\
Guangdong-style & Azelaic acid & & Adipic acid, Azelaic acid \\
Western fast food & Adipic acid, Suberic acid & &
\end{tabular}

meat increased the production of C25. Second, compared with Chinese cooking, Western cooking produced higher concentration of n-alkanes. This was 2-3 times higher than that in Chinese food (Zhao et al., 2007b). Third, n-alkanes had a significant parity advantage in the study of Chinese cooking (Zhao et al., 2015; Pei et al., 2016). In the study of Western cooking, it was found that n-alkanes also reflected the parity advantage but not as obvious as Chinese cooking (Poon et al., 2016). In the analysis of Zhao et al. (2007b) the carbon dominance index (CPI) was 3.02. If food contains only a small amount of vegetables, a high CPI can be achieved. In Western cooking, the CPI value was lower (1.08-1.62).

According to the previous studies, monosaccharide anhydrides were not produced when cooking meat (Rogge et al., 1993; Schauer et al., 1999). As Chinese cuisine uses more vegetables and Western cooking uses more meat, it can be inferred from the above research results that the concentration of monosaccharide anhydrides and phytosterols in the particles produced in Chinese cooking should be higher. Additionally, the concentration of the above two types of substances in Western cooking should be lower but with higher concentrations of cholesterol. In the site testing of Western-style fast food restaurants, $\beta$-sitosterol was not found, while $\beta$-sitosterol was the most common phytosterol in Chinese cooking. Additionally, the concentration of $\beta$-sitosterol was lower than that in normal Chinese cooking, while cholesterol was higher than that in Chinese cooking (Zhao et al., 2007b). These test results are consistent with previous research results. In all tests, levoglucan had the highest concentration among monosaccharide anhydrides, and $\beta$-sitosterol had the highest concentration among sterols (He et al., 2004; Zhao et al., 2007b; Pei et al., 2016).

\section{Others}

Due to the combined effects of many factors, significant differences were observed among the different cooking conditions. This created challenges for sampling conditions (Zhao et al., 2015; Cheng 2018; Huan et al., 2019). For most pollutants, the emission factors from the controlled tests in experiments were much lower than those from uncontrolled burning tests in real-world (Du et al., 2018b).
The studies conducted by Sjaastad et al. (2008) and Svendsen et al. (2002) showed that exposure to the cooking fumes of frying pan in the residential kitchen may be similar or even higher than cooking in commercial kitchen. However, the concentration of particulate matter monitored in rooftop exhaust from Chinese domestic cooking was one order of magnitude lower than that from commercial cooking (He et al., 2004), indicating fewer particle emissions from some domestic cooking and better capture efficiency of the hood in the commercial applications. Zhao et al. (2015) also found that the mass concentration of particulates produced in the home kitchen was lower than that in commercial kitchens. The study conducted by Sharma and Jain (2019) concluded that usage of efficient designing of the kitchen structure coupled with improved cook stoves could improve the overall indoor air quality of the household. Food consumption also affects the production of cooking particles. The concentrations of $\mathrm{PM}_{2.5}$ and $\mathrm{PM}_{10}$ were elevated with the increase in fried potatoes $(1.25 \mathrm{~kg}-$ $3.75 \mathrm{~kg}$ ) (Sofuoglu et al., 2015). However, Chen et al. (2018) found that, when the ingredient weights were large (for 25 persons), the emission rates of $\mathrm{PM}_{2.5}$ were significantly lower than those of the weight for 1 person.

\section{KITCHEN VENTILATION}

\section{Hood Performance}

An efficient ventilation system is quite necessary to provide a comfortable, healthy and energy-efficient working environment (Kotani et al., 2009; Han et al., 2019). One significant element in the creation of a healthy working environment in the kitchen is the exhaust hood, which could significantly reduce the personal PM exposure (Poon et al., 2016; Du et al., 2017). Scholars have conducted much research on measures to improve the efficiency of fume extraction. Tables 7 and 8 present the improvement measures in kitchen ventilation. Possible solutions have been recommended as follows:

\section{Positioning the Cooking Appliance}

The purpose of positioning the appliance is to make the thermal fume flow within the size of the exhaust hood to 


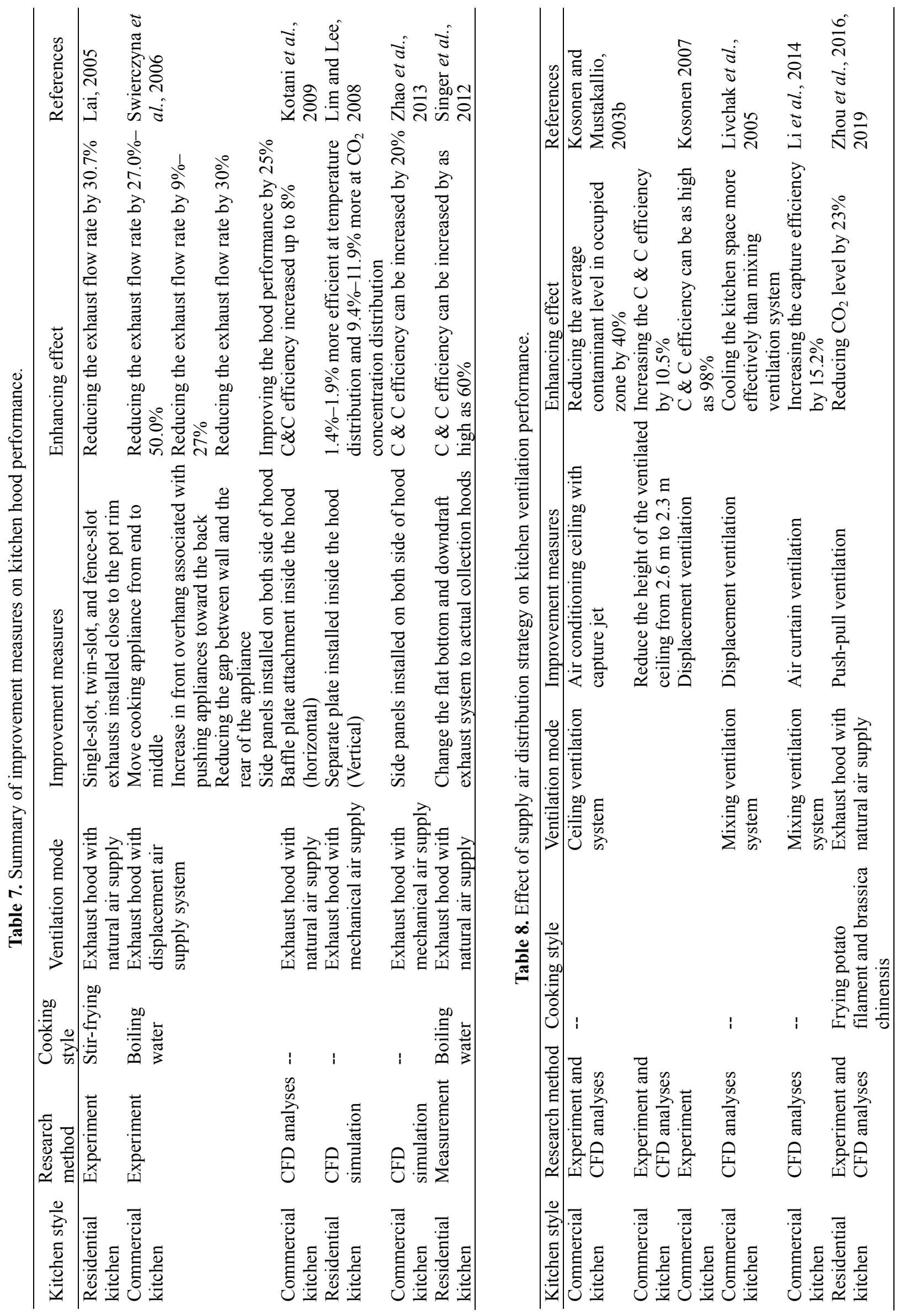


improve the capture performance as much as possible. The ASHRAE research project RP-1202 (2006) has quantified the effect of the location and combination of cooking appliances on the minimum capture and containment (C \& C) efficiency of hood. Based on the research conclusions, some suggestions are given:

a. Locating heavy-load cooking appliances near the center of the cooking appliance line.

b. Moving the cooking appliance from end to middle.

c. Reducing the gap between wall and rear of the appliance.

d. Increasing the front overhang of hood associated with pushing appliances toward the back.

\section{Installing Attachments}

Attachments are not an integral part of exhaust hoods. However, many studies have found that adding diverse attachment components helps to increase the C \& C efficiency of the hood (Fig. 1). Project RP-1202 (2006) investigated the effects of rear seals, front overhang and side panels. Side exhaust systems were investigated by Lai (2005) to investigate the effect of different exhaust configurations on hood performance. Lim and Lee (2008) conducted a three-dimensional numerical analysis to study how to use a separation plate to improve the exhaust hood system to more effectively eliminate pollution. An exhaust hood with a high capture efficiency was developed by Kotani et al. (2009) using a baffle plate inside the exhaust hood. The results of these studies provide suggestions for HVAC designers to improve the performance of the kitchen ventilation system.

\section{Changing the Shape of the Exhaust Hood}

There are two ways for hoods to exhaust the COFs: top exhaust and side exhaust. It is popular to use side exhaust hood in residential kitchen because it can save top space. Most commercial kitchens use top exhaust hood, which can also be divided into two types: canopy hood/umbrella- shape hood (Chinese style) and box hood (American or European style). The grease filter and front edge of the canopy hood constitute a triangle to reduce the flow resistance of exhaust air flow and avoid the captured grease that adheres to the top of hood falling into the wok. Considered from another aspect, to ensure a sufficiently large hood volume, the cross section of the American- or European-style exhaust hood is designed as a rectangle. Fig. 2 shows the common used exhaust hood in commercial kitchens. To fully understand the influence of the hood volume on the C \& C efficiency, Zhao et al. (2013) studied 21 types of volumes from canopy hood to box hood as shown in Fig. 3. The results showed that the small hood volume of traditional Chinese-style hoods did not reduce the C \& C efficiency. Tsai and Hsieh (2006) studied the flow field of the exhaust hood induced by the combination of crosswind and extract flow. The results found that the flow field would be affected by the oblique angle of the hood's set-up. These studies on the shape of hood gave the following suggestions (Swierczyna, 2006):

a. Increasing the depth of hood (from front to back) improves the performance of hood. This additional depth of hood should be used as much as possible to increase the size of the front overhang.

b. Increasing the height of hood to increase the volume so that the thermal plume is evenly distributed along the filtering device to improve hood C \& C efficiency.

\section{Positioning the Exhaust Hood}

Mounting hood at the lowest practical (or allowable) height, minimizing the distance from cooking surface to hood to improve the hood performance.

a. Installing side panels on both sides of the hood;

b. Installing baffle plate inside the hood (horizontal);

c. Installing separate plate inside the hood (Vertical);

d. For side exhaust systems, installing single-slot, twinslot, and fence-slot exhausts close to the pot rim;

e. Mounting shelves or attachments on or behind the oven.

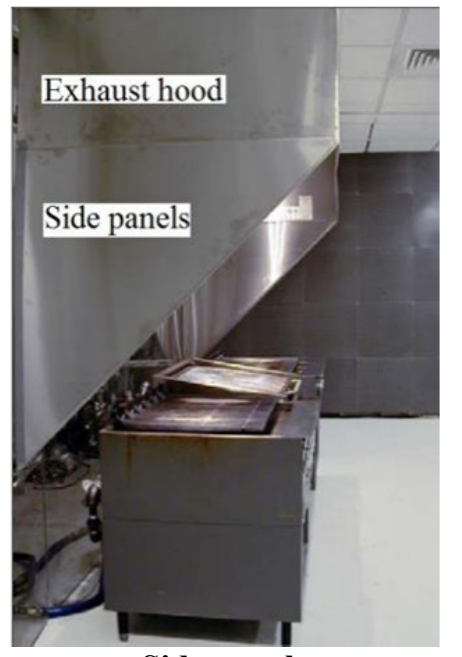

Side panels

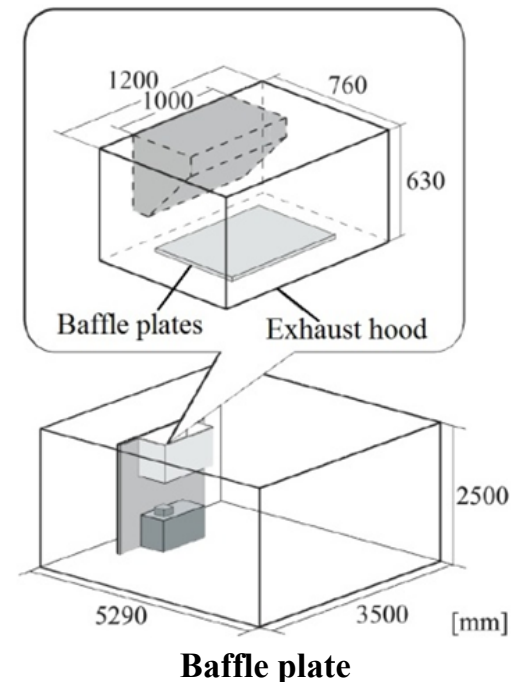

Baffle plate

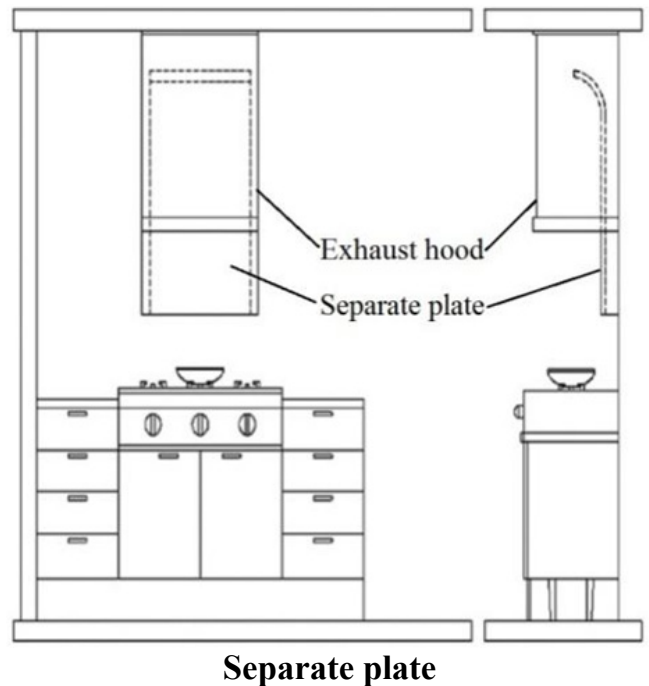

Separate plate

Fig. 1. Schematics of side panels, baffle plate and separate plate (Swierczyna et al., 2006; Lim and Lee 2008; Kotani et al., 2009). 


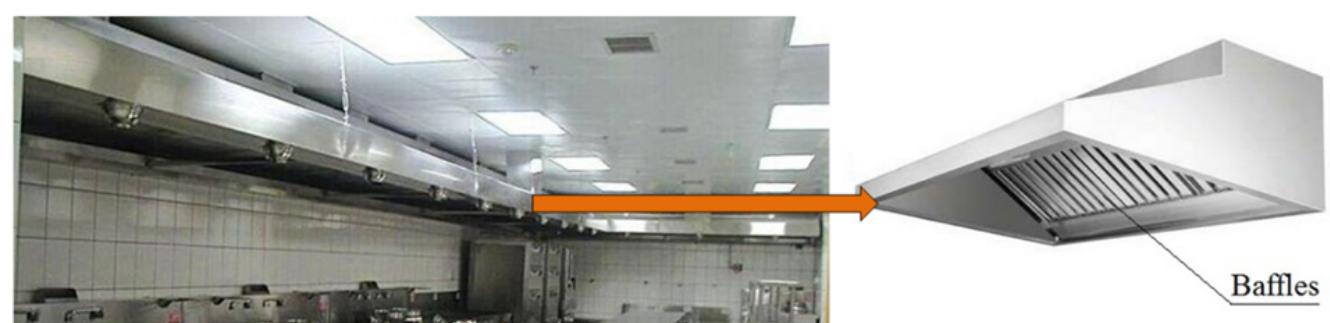

The grease filter and the front edge of the hood constitute a triangle that would make a small hood volume.

Umbrella - shape hood

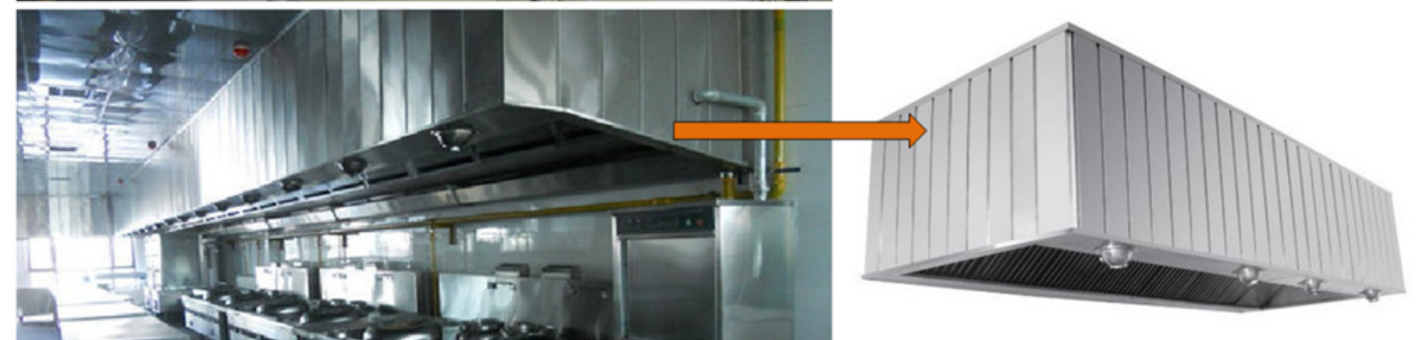

The cross profile of American or European style of cooking hood usually is rectangle.

\section{Rectangular - shape hood}

Fig. 2. The types of exhaust hood commonly used in the commercial kitchens.
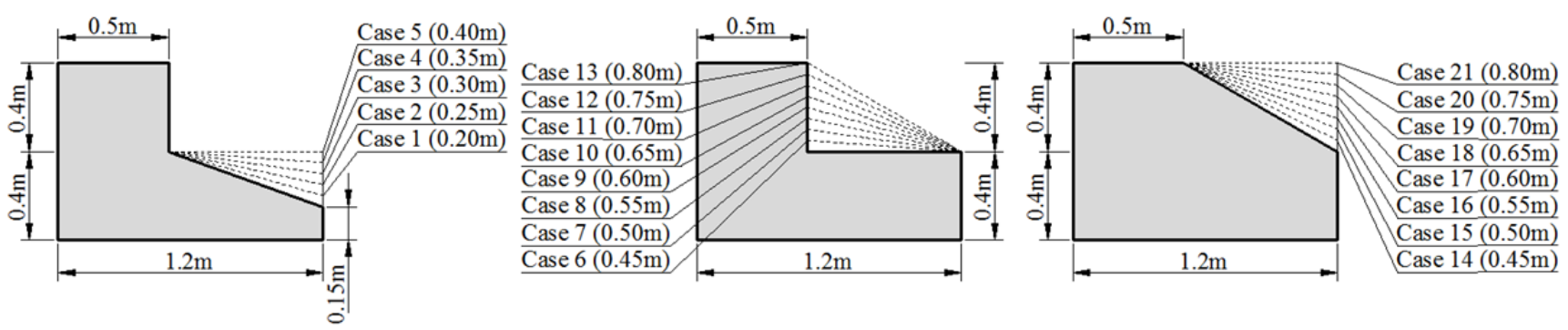

Fig. 3. Schematic of the volume change from canopy hood to box hood (Zhao et al., 2013).

\section{Exhaust Hood Connection}

The connection between the exhaust hood and fan or exhaust duct has a nonnegligible impact on the $\mathrm{C} \& \mathrm{C}$ efficiency. Chao and Law (2000) investigated the effect of direct or indirect connection of hood on the efficiency of pollutant removal. Two different arrangements of the exhaust duct whether located on the upper side or rear part of the hood has been studied by Zhao et al. (2013). The results of these studies produced the following recommendations:

a. A hood directly connected to the exhaust fan is more effective than a hood that is not directly connected or a kitchen with only a window-mounted exhaust fan.

b. Compared with the upper side, when the exhaust duct is located at the rear of hood, the hood C \& $\mathrm{C}$ efficiency is enhanced.

\section{Increasing the Exhaust Fan Speed}

The exhaust speed is crucial for hood C \& C efficiency.
Obviously, the higher the speed of the exhaust hood is, the higher the C \& C efficiency is. Singer et al. (2012) evaluated the correlation between the $\mathrm{C} \& \mathrm{C}$ efficiency and fan speed in residential field experiments. As expected, higher $\mathrm{C} \& \mathrm{C}$ efficiencies were achieved with higher fan speeds and related higher air flow rates. However, it is worth noting that high exhaust air speeds can lead to huge energy consumption in kitchen ventilation system. In Chinese commercial kitchens, the design exhaust airflow rate reaches $60 \mathrm{~h}^{-1}$, and, in actual projects, it even reaches $80 \mathrm{~h}^{-1}$. The ventilation energy consumption accounts for $30-40 \%$ of the total energy consumption of restaurant industry, resulting in unnecessary economic waste. The latest research indicated that extending the running time of the exhaust hood had the same effect as increasing exhaust flow rate to reduce particle exposure. For $\mathrm{PM}_{2.5}$, the effect of running an exhaust fan for 15 min after cooking was similar in magnitude to the impact of a 100-cfm increase in the flow rate used 
while cooking (Dobbin et al., 2018). On this basis, it is necessary to further analyze the energy consumption of kitchen ventilation system to determine the best operation scheme.

In addition to the above improvement measures, scholars have also studied the influence of operators on the $\mathrm{C} \& \mathrm{C}$ efficiency of exhaust hoods. Experiments were conducted by Huang et al. (2010) to investigate the relative magnitudes and physical mechanisms of hood spillages. The results indicated that COFs would attach to the mannequin's body standing in front of the cooking appliance. Through the front edge of hood where the mannequin was standing, the attached COFs induced room air and created remarkable dispersion of COFs into the environment. Singer et al. (2012) also found that the presence and movement of cooks in front of the appliance may interfere with airflow fields and affect $\mathrm{C} \& \mathrm{C}$ efficiency.

\section{Supply Air Distribution Strategy}

Many engineers and designers have the misconception that poor indoor air quality and thermal environment in kitchen are only related to exhaust hood itself. They do not realize the negative impact of bad air distribution on the hood performance. Without makeup air system, the exhaust hood was not able to decrease the particle concentration effectively during the cooking period (Kang et al., 2019). The supply air distribution strategy has a significant influence on the pollutant removal effectiveness in a kitchen environment (Pekkinen et al., 1992; Kosonen, 2007; Stabile et al., 2015). The following provides several ways to help increase the efficiency of exhaust hoods.

\section{Air-conditioning Ceiling with Capture Jet}

The effect of an air-conditioning ceiling with a capture jet on the containment efficiency was conducted with laboratory measurements and CFD simulations by Kosonen (2007), as shown in Fig. 4 (Kosonen, 2007). When the cooking heat loads are relatively low and the bottom space of the kitchen is limited, the ventilated ceiling, which can help to enhance the efficiency of the kitchen ventilation system, is an availably choice for kitchen ventilation. The capture jet flows horizontally across the ceiling to helping direct the air impurities and convection heat towards the exhaust opening. A combined ventilated ceiling and capture jet can reduce the average contaminant level of the occupied zone by $40 \%$.

\section{Push-pull Ventilation}

A push-pull ventilation system consisting of a range hood combined with the air supply through a slot air curtain was proposed by Zhou et al. (2016, 2019). It can effectively reduce the indoor $\mathrm{CO}_{2}$ level by $23.0 \%$. The result suggested that utilization of the air curtain can effectively improve the performance of the exhaust hood. The schematic diagram of the push-pull ventilation system is presented in Fig. 5.

\section{Thermal Displacement Ventilation and Air Curtain Ventilation}

Mixing ventilation is the most widely used system in commercial kitchens. Cold air is supplied through ceiling diffusers at a high discharge velocity. The cross-drafts and unwanted air movement in the kitchen are caused by a high-momentum air jet that makes it difficult to capture the pollutants emitted from the cooking process with range hoods (Livchak et al., 2005). There is a misconception that many designers and engineers believe that they may use the airflow from ceiling diffusers to "cool" the chef. However, they do not realize its negative impact on the exhaust hood performance (Li et al., 2012a). Thermal displacement ventilation (TDV) is an alternative air distribution system that is better suitable for the kitchen environment (Li et al., 2012b). The hood exhaust airflow can be reduced by $12.5 \%$ (VDI 2052), when mixed ventilation is replaced with TDV in kitchen. Additionally, the TDV mode with a high ventilation efficiency $(98.0 \%)$ can cool the kitchen space more effectively (Livchak et al., 2005; Kosonen, 2007). However, in practice, because of the space constraint in kitchen, the utilization of a TDV system may be difficult. A new air distribution pattern named air curtain ventilation (ACV) was proposed by Li et al. (2014) as shown in Fig. 6. It is regarded as a combination of the

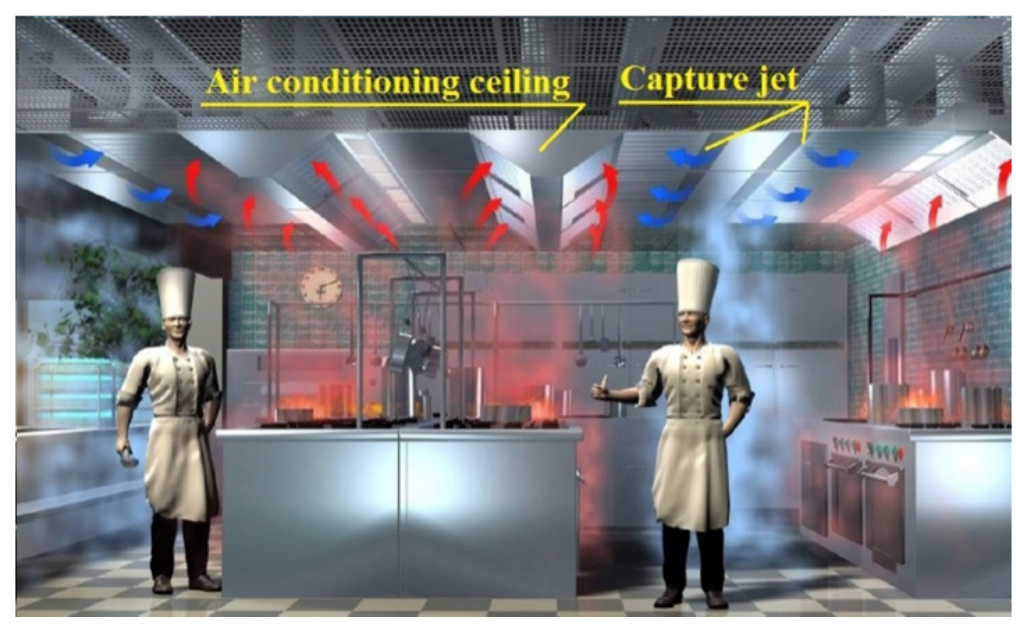

Fig. 4. Air conditioning ceiling with capture jet system in commercial kitchen (Kosonen, 2007). 


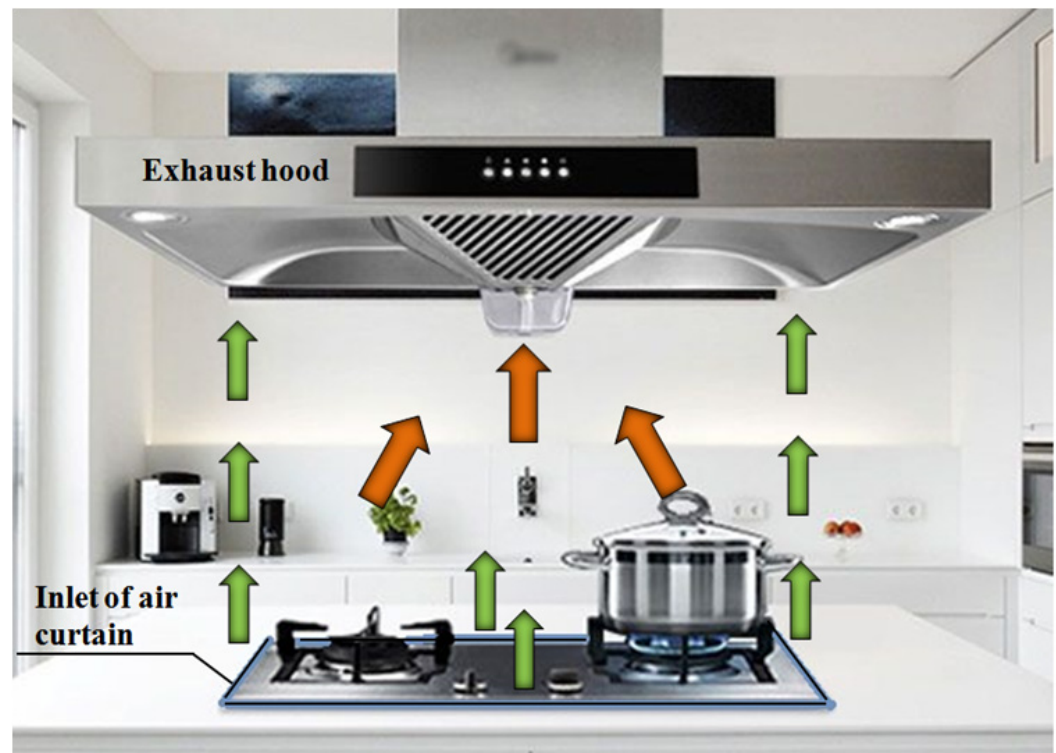

Fig. 5. Schematic diagram of push-push ventilation system (Zhou et al., 2016).
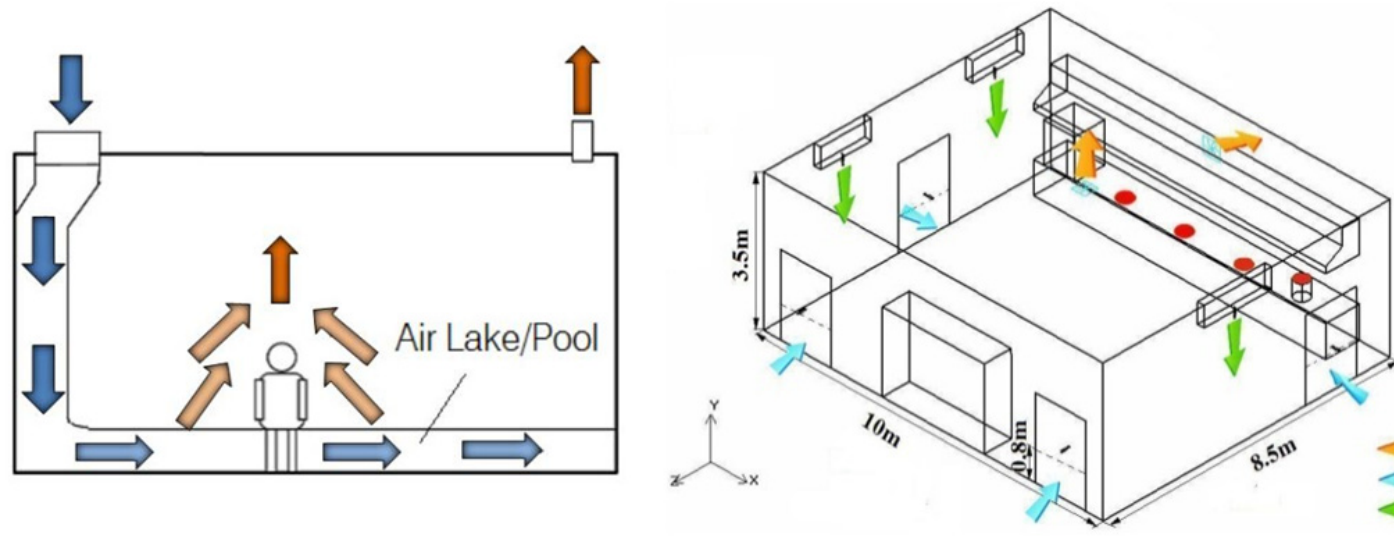

Exhaust Air Makeup Air Supply Air

Fig. 6. Schematic diagram of air curtain ventilation in kitchen.

displacement flow and mixing flow. Due to Coanda effect, the "air pool" or "air lake" phenomenon created by air curtain ventilation is somewhat similar to displaced air movement. The $\mathrm{C} \& \mathrm{C}$ efficiency could be increased by $15.2 \%$, when the air curtain ventilation system is used in commercial kitchen environment.

\section{Evaluation Index}

In practice, the main purpose of kitchen ventilation is to extract the contaminants and convective heat sufficiently from working area with a minimum air flow rate. The capture efficiency is a basic indicator of the local exhaust ventilation performance (Kotani et al., 2009). ASTM 1704 defines the "Hood capture and containment (C \& C)" as "the ability of the hood to capture and contain grease laden cooking vapors, convective heat and other products of cooking processes" (Zhou et al., 2016).

The Schlieren visualization system complementing the heat gain testing capabilities were incorporated into the Commercial Kitchen Ventilation (CKV) laboratory for capture and containment testing in the ASTM Standard
F1704-99. Additional laboratory data to improve ASHRAE documentation (ASTM F1704-99) for general hood capture and containment exhaust rates and values for appliance heat gain to the space were conducted by Swierczyna et al. (1997) and Fisher (1998) respectively. Different from previous studies, a measurement method for $\mathrm{C} \& \mathrm{C}$ efficiency under practical indoor conditions has been developed by Knappmiller and Schrock (1997). However, one current limitation for ASTM 1704 is that it was designed for mixing air-conditioning systems with exhaust-only hoods.

In Europe, the Verein Deutscher Ingenieure Standard (VDI 2052) was used to determine the $C \& C$ requirements for range hoods. In VDI 2502, the main parameters for the airflow calculation are the convective heat load of cooking appliances and distance between the hood and appliance. The engineered procedure is used in some codes (AS 1668.2-2002) for the kitchen hood design. The utilization of suitable technology or solutions is allowed to achieve the designated targets. However, the technology or solutions should be proven with appropriate calculations or reviewed in the field. 
In the literature, there is substantial definitions of $\mathrm{C} \& \mathrm{C}$ efficiency and general local exhaust systems for kitchen exhaust hoods (Farnsworth et al., 1989, Geerinckx et al., 1991). They could evaluate the performance of exhaust hoods and could be used for the practical design. The two formulas summarized and proposed by Geerinckx et al. (1991) used the perfect mixing situation without a hood as a reference. Jansson (1990) defined the C \& C efficiency of the exhaust hood as the ratio of directly captured pollutants to the total amount pollutants of the sources, which is consistent with Geerinckx's theory. The concept of the direct capture efficiency was further studied by Madsen et al. (1994). However, it is difficult to separate the directly captured pollutants from the total generated pollutants, not only regarding the measurement but also the numerical simulation. Wolbrink and Sarnosky (1992) derived the $\mathrm{C} \& \mathrm{C}$ efficiency in a confined space, where a two-zone mixing model based on mass conservation was assumed. The method has been widely applied in many studies to evaluate the performance of range hoods. Li and Delsante (1996) further derived the formula, making it suitable for general ventilation systems. Based on Li's study, Kosonen and Mustakallio (2003) derived the deduced C \& C efficiency formula for the ceiling ventilation system in a confined space.

Due to the loss of particles deposited in the exhaust hood and pipe, the efficiency of capturing cooking particles is quite different from that of gaseous pollutants. A few studies have reported on the effectiveness of exhaust hoods at reducing the concentrations of cooking particles (Sjaastad and Svendsen, 2010; Delp and Singer, 2012). The C \& C efficiency of particles should be achieved indirectly by comparing the concentration of PM in the room when the exhaust hood is used with the concentration under the same cooking condition when the exhaust hood is not used (Lunden et al., 2014).

\section{CONCLUSIONS}

In cities and rural areas worldwide, cooking has proven to be an important source of indoor and outdoor PM. The apportionment studies that identified this source primarily used source profiles from the United States, Europe, and Asia because many studies were conducted in these regions.

Further understanding of the physicochemical components associated with cooking sources facilitates the assessment of human exposure, health injury and environmental impact under cooking conditions. This review found that the composition of cooking aerosol particles is highly diverse, depending on the fuel type, cooking oil (if used), cooking temperature, cooking method, cooking style (raw food ingredient) and other factors. This diversity means that prediction and evaluation of the cooking aerosol are very difficult, although the characteristics of the cooking source are well known.

The submicron particles that have a small natural sedimentation rate and follow the movement rule of fluid account for more than $90 \%$ of the cooking particles. It is not only difficult to be captured and purified by the ventilation system but also more easily inhaled by the human body or in contact with the skin surface. In addition, the cooking particles are affected by ventilation and thermal plume at high temperatures, and their growth and diffusion characteristics are significantly different from other indoor particles. Therefore, it is difficult to achieve high C \& C efficiency of cooking particles in real situations. Presently, improvement measures and air supply strategy of kitchen ventilation systems have been studied through experiments and numerical simulation methods.

\section{EXPECTATION}

Cooking oil fumes are aerosols comprising particles, droplets, and gaseous companion products, which are recognized as a significant pollutants source. Diffusion and transmission of COFs is a complex process involves physical and chemical reactions. Evaluate and control of COFs requires an in-depth understanding of numerous cooking processes, chemistry, fluid mechanics, and thermodynamics.

Most studies on COFs' characteristic currently focused on the particulate matter and mainly consider the particles concentration, chemical composition and human exposure. Cooking particles interact with each other during transport, and their related parameters change and ultimately affect the removal and purification of particles. Theoretical and experimental research is needed on the growth and evolution of cooking particles in order to further study the emission characteristics of each component, including: physical and chemical. Further research on the accurate prediction model of the diffusion of cooking particles is needed.

Furthermore, the existing kitchen (residential or commercial) exhaust hood design method and exhaust flow rate calculation method are all based on the thermal plume generated during cooking process, without considering the entrainment and sliding between particles and ambient air. There are obvious differences between the control of cooking particles and the control of gaseous pollutants. However, the existing kitchen ventilation design specifications has hardly involved in the relevant content, resulting in the low $\mathrm{C} \& \mathrm{C}$ efficiency of cooking particles. Research is needed on the coupling mechanism of particle group and ambient air in order to study the ventilation control of cooking particles. The structure design, flow rate and C \& C efficiency of the exhaust hoods in the current literature varies greatly, and further research is needed for exploring the appropriate design method to reduce exhaust air flow rate and exposure to cooking pollutants. In addition, in the future, the energy consumption analysis in kitchens, especially in commercial kitchens, is needed. Exposure to pollutants, kitchen ventilation patterns and system energy consumption are interrelated. The kitchen ventilation should be given more attention because it is the key to solve the problem.

\section{ACKNOWLEDGMENT}

This research was supported by the National Natural 
Science Foundation of China (No. 51504182, 51674188, 51874229, 51404191), Shaanxi Innovative Talents Cultivate Program-New-star Plan of Science and Technology (2018KJXX-083), Scientific Research Program funded by the Shaanxi Provincial Education Department (No. 19JK0543), Scientific Research Program funded by Xi'an Science and Technology Bureau (Grand No. 201805036YD14CG20(5)) and Outstanding Youth Science Fund of Xi'an University of Science and Technology (No. 2018YQ2-01). This research was also supported by the National Research Council of Science \& Technology (NST) grant by the Korea government (MSIP) (No. CRC-16- 38502-KICT).

\section{REFERENCES}

Abdullahi, K.L., Delgado-Saborit, J.M. and Harrison, R.M. (2013). Emissions and indoor concentrations of particulate matter and its specific chemical components from cooking: A review. Atmos. Environ. 71: 260-294.

Abt, E., Suh, H.H., Allen, G. and Koutrakis, P. (2000). Characterization of indoor particle sources: A study conducted in the metropolitan Boston area. Environ. Health Perspect. 108: 35-44.

Acciai, C., Zhang, Z., Wang, F., Zhong, Z. and Lonati, G. (2017). Characteristics and source analysis of trace elements in $\mathrm{PM}_{2.5}$ in the urban atmosphere of Wuhan in spring. Aerosol Air Qual. Res. 17: 2224-2234.

Alessandrini, F., Schulz, H., Takenaka, S., Lentner, B., Karg, E., Behrendt, H. and Jakob, T. (2006). Effects of ultrafine carbon particle inhalation on allergic inflammation of the lung. J. Allergy Clin. Immunol. 117: 824-830.

Anwar, F., Kazi, T.G., Saleem, R. and Bhanger, M.I. (2004). Rapid determination of some trace metals in several oils and fats. Grasas Y Aceites. 55: 160-168.

Arbex, M.A., Martins, L.C., Pereira, L.A.A., Negrini, F., Cardoso, A.A., Melchert, W.R., Arbex, R.F., Saldiva, P.H.N., Zanobetti, A. and Braga, A.L.F. (2007). Indoor $\mathrm{NO}_{2}$ air pollution and lung function of professional cooks. Braz. J. Med. Biol. Res. 40: 527-534.

AS 1668.2-2002. (2002). The Building Code of Australia: Part F4-Light and Ventilation, Australian Standard.

ASTM (1999). Standard F1704-99: Standard test methods for performance of commercial kitchen ventilation systems. United States.

Atta, M.B., El-Sebaie, L.A., Noaman, M.A. and Kassab, H.E. (1997). The effect of cooking on the content of heavy metals in fish (Tilapia nilotica). Food Chem. 58: $1-4$.

Beck-Speier, I., Dayal, N., Karg, E., Maier, K.L., Schumann, G., Schulz, H., Semmler, M., Takenaka, S., Stettmaier, K., Bors, W., Ghio, A., Samet, J.M. and Heyder, J. (2005). Oxidative stress and lipid mediators induced in alveolar macrophages by ultrafine particles. Free Radical Biol. Med. 38: 1080-1092.

BJC/OR-271 (1999). Guidance for conducting risk assessments and related risk activities for the DOE-ORO environmental management program. U.S. Department of Energy.

Brauer, M., Bartlett, K., Regalado-Pineda, J. and PerezPadilla, R. (1996). Assessment of particulate concentrations from domestic biomass combustion in rural Mexico. Environ. Sci. Technol. 30: 104-109.

Buonanno, G., Morawska, L. and Stabile, L. (2009). Particle emission factors during cooking activities. Atmos. Environ. 243: 3235-3242.

Buonanno, G., Johnson, G., Morawska, L. and Stabile, L. (2011). Volatility characterization of cooking-generated aerosol particles. Aerosol Sci. Technol. 45: 1069-1077.

Buonanno, G., Morawska, L., Stabile, L. and Viola, A. (2010). Exposure to particle number, surface area and PM concentrations in pizzerias. Atmos. Environ. 44: 3963-3969.

Chao, Y.H. and Law, A. (2000). A study of personal exposure to nitrogen dioxide using passive samplers. Build. Environ. 35: 545-553.

Chen, C., Zhao, Y. and Zhao, B. (2018). Emission rates of multiple air pollutants generated from Chinese residential cooking. Environ. Sci. Technol. 52: 1081-1087.

Chen, C.Y., Kuo, Y.C., Wang, S.M., Wu, K.R., Chen, Y.C. and Tsai, P.J. (2019). Techniques for predicting exposures to polycyclic aromatic hydrocarbons (PAHs) emitted from cooking processes for cooking workers. Aerosol Air Qual. Res. 19: 307-317.

Cheng, J.H., Lee, Y.S. and Chen, K.S. (2016). Carbonyl compounds in dining areas, kitchens and exhaust streams in restaurants with varying cooking methods in Kaohsiung, Taiwan. J. Environ. Sci. 41: 218-226.

Cheng, M.D. (2018). Selective collection of airborne particulate matter. Aerosol Air Qual. Res. 18: 1361-1365.

Chiang, T.A., Wu, P.F., Ying, L.S., Wang, L.F. and Ko, Y.C. (1999). Mutagenicity and aromatic amine content of fumes from heated cooking oils produced in Taiwan. Food Chem. Toxicol. 37: 125-134.

Chowdhury, Z., Le, L.T., Masud, A.A., Chang, K.C., Alauddin, M., Hossain, M., Zakaria, A.B.M. and Hopke, P.K. (2012). Quantification of indoor air pollution from using cookstoves and estimation of its health effectson adult women in Northwest Bangladesh. Aerosol Air Qual. Res. 12: 463-475.

Delp, W.W. and Singer, B.C. (2012). Performance assessment of U.S. residential cooking exhaust hoods. Environ. Sci. Technol. 46: 6167-6173.

Dobbin, N.A., Sun, L., Wallace, L., Kulka, R., You, H., Shin, T., Aubin, D., St-Jean, M. and Singer, B.C. (2018). The benefit of kitchen exhaust fan use after cooking - An experimental assessment. Build. Environ. 135: 286-296.

Du, B., Gao, J., Chen, J., Stevanovic, S., Ristovski, Z., Wang, L. and Wang, L. (2017). Particle exposure level and potential health risks of domestic Chinese cooking. Build. Environ. 123: 564-574.

Du, W., Li, X. and Chen, Y. (2018a). Household air pollution and personal exposure to air pollutants in rural China - A review. Environ. Pollut. 237: 625-638.

Du, W., Zhu, X., Chen, Y.C., Liu, W.J., Wang, W., Shen, G.F., Tao, S. and Jetter, J.J. (2018b). Field-based 
emission measurements of biomass burning in typical Chinese built-in-place stoves. Environ. Pollut. 242: 1587-1597.

Dugo, G., Pellicano, T.M., La, Pera, L., Lo, Turco, V., Tamborrino, A. and Clodoveo, M.L. (2007). Determination of inorganic anions in commercial seed oils and in virgin olive oils produced from de-stoned olives and traditional extraction methods using suppressed ion exchange chromatography (IEC). Food Chem. 102: 599-605.

Farnsworth, C., Waters, A., Kelso, R.M. and Fritzsche D. (1989). Development of a fully vented gas range. ASHRAE Trans. 95: 759-768.

Fisher, D.F. (1998). New recommended heat gains for commercial cooking equipment. ASHRAE Trans. 104: 953-960.

Gao, J., Cao, C.S., Wang, L., Song, T.H., Zhou, X., Yang, J. and Zhang, X. (2013). Determination of size-dependent source emission rate of cooking-generated aerosol particles at the oil-heating stage in an experimental kitchen. Aerosol Air Qual. Res. 13: 488-496.

GB 3095-2012 (2012). Ambient air quality standards. China.

Geerinckx, B., Wouters, P. and Vandaele, L. (1991). Efficiency measurement of kitchen hoods. Air Infiltration. 13: $15-17$.

Giwa, S.O., Nwaokocha, C.N. and Odufuwa, B.O. (2019). Air pollutants characterization of kitchen microenvironments in southwest Nigeria. Build. Environ. 153: 138-147.

Glytsos, T., Ondracek, J., Dzumbova, L., Kopanakis, I. and Lazaridis, M. (2010). Characterization of particulate matter concentrations during controlled indoor activities. Atmos. Environ. 44: 1539-1549.

Han, O., Li, A.G. and Kosonen, R. (2019). Hood performance and capture efficiency of kitchens: A review. Build. Environ. 161: 106-221.

Hao, X.W., Li, J. and Yao, Z.L. (2016). Changes in PAHs levels in edible oils during deep-frying process. Food Control. 66:233-240.

He, L.Y, Hu, M., Huang, X.F., Yu, B.D., Zhang, Y.H. and Liu, D.Q. (2004). Measurement of emissions of fine particulate organic matter from Chinese cooking. Atmos Environ. 38:6557-6564.

Ho, S.S.H., Yu, J.Z., Chu, K.W. and Yeung, L.L. (2006). Carbonyl emissions from commercial cooking sources in Hong Kong. J. Air Waste Manage. Assoc. 56: 10911098.

Hu, D., Bian, Q.J., Lau, A.K.H. and Yu, J.Z. (2012). Source apportioning of primary and secondary organic carbon in summer $\mathrm{PM}_{2.5}$ in Hong Kong using positive matrix factorization of secondary and primary organic tracer data. J. Geophys. Res. 115: D16204.

Huan, C., Wang, F., Li, S., Zhao, Y., Liu, L., Wang, Z. and Ji, C. (2019). A performance comparison of serial and parallel solar-assisted heat pump heating systems in Xi'an, China. Energy Sci. Eng. 00: 1-15, doi: 10.1002/e se3.357.

Huang, H.L., Lee, W.G. and Wu, F.S. (2016). Emissions of air pollutants from indoor charcoal barbecue. J. Hazard. Mater. 302: 198-207.

Huang, R.F., Dai, G.Z. and Chen, J.K. (2010). Effects of mannequin and walk-by motion on flow and spillage characteristics of wall-mounted and jet-isolated range hoods. Ann. Occup. Hyg. 54: 625-639.

Huang, Y., Ho, S.S.H., Ho, K.F., Lee, S.C., Yu, J.Z. and Louie, P.K.K. (2011). Characteristics and health impacts of VOCs and carbonyls associated with residential cooking activities in Hong Kong, J. Hazard. Mater. 186: 344-351.

Huboyo, H.S., Tohno, S. and Cao, R. (2011). Indoor $\mathrm{PM}_{2.5}$ characteristics and $\mathrm{CO}$ concentration related to waterbased and oil-based cooking emissions using a gas stove. Aerosol Air Qual. Res. 11: 401-411.

IARC (2010). Household use of solid fuels and hightemperature frying. International Agency for Research on Cancer. Lyon.

Jansson, A. (1990). Local exhaust ventilation and aerosol behavior in industrial workspace air. School of Civil Engineering. Royal Institute of Technology, Stockholm, Sweden.

Kang, K., Kim, H., Kim, D.D., Lee, Y.G. and Kim, T. Characteristics of cooking-generated $\mathrm{PM}_{10}$ and $\mathrm{PM}_{2.5}$ in residential buildings with different cooking and ventilation types. Sci. Total Environ. 668: 56-66.

Karimatu, L.A., Juana, M.D.S. and Roy, M.H. (2013). Emissions and indoor concentrations of particulate matter and its specific chemical components from cooking: A review. Atmos. Environ. 71: 260-294.

Katragadda, H.R., Fullana, A., Sidhu, S. and CarbonellBarrachina, A.A. (2010). Emissions of volatile aldehydes from heated cooking oils. Food Chem. 120: 59-65.

Kawashima, L.M. and Valente Soares, L.M. (2003). Mineral profile of raw and cooked leafy vegetables consumed in Southern Brazil. J. Food Compos. Anal. 16: 605-611.

Kima, K.H., Pandey, S.K., Kabir, E., Susaya, J. andBrown, R.J.C. (2011). The modern paradox of unregulated cooking activities and indoor air quality. J. Hazard. Mater. 195: 1-10.

Knappmiller, K. and Schrock, D. (1997). Heat gain testing to energy balance protocol. Final report. August 1995 February 1997.

Ko, Y.C., Cheng, L.S., Lee, C.H., Huang, J.J., Huang, M.S., Kao, E.L., Wang, H.Z. and Lin, H.J. (2000). Chinese food cooking and lung cancer in women nonsmokers. Am. J. Epidemiol. 151: 140-147.

Kosonen, R. and Mustakallio, P. (2003). Analysis of capture and containment efficiency of a ventilated ceiling. Int. J. Vent. 2: 33-44.

Kosonen, R. (2007). The effect of supply air systems on the efficiency of a ventilated ceiling. Build. Environ. 42: 1613-1623.

Kotani, H., Yamanaka, T., Sagara, K. and Chihara, S. (2009). High efficiency exhaust hood with baffle plate for commercial kitchen, The 9th International Conference on Industrial Ventilation, Japan.

Kurabuchi, T., Okuda, A., Aizawa, Y., Sakamoto, A., Endo, 
T. and Kondo, Y. (2007). Influence of cooking operation on indoor environment of house kitchens and living rooms Part II: Measurement methods of capture efficiency under actual room condition. Summaries of Technical Papers of Annual Meeting AIJ, D, pp. 707708. (in Japanese).

Lai, C.M. (2005). Assessment of side exhaust system for residential kitchens in Taiwan. Build. Serv. Eng. Res. Technol. 26: 157-166.

Lee, S.C., Li, W.M. and Chan, L.Y. (2001). Indoor air quality at restaurants with different styles of cooking in metropolitan Hong Kong. Sci. Total Environ. 279: 181193.

Levy, J.I., Dumyahn, T. and Spengler, J.D. (2002). Particulate matter and polycyclic aromatic hydrocarbon concentrations in indoor and outdoor microenvironments in Boston, Massachusetts. J. Exposure Sci. Environ. Epidemiol. 12: 104-114.

Li, A.G., Zhao, Y.J., Jiang, D.H. and Hou, X.T. (2012a). Measurement of temperature, relative humidity, concentration distribution and flow field in four typical Chinese commercial kitchens. Build. Environ. 56: 139150.

Li, A.G., Yin, H.G. and Zhang, W.D. (2012b). A novel air distribution method - Principles of air curtain ventilation. Int. J. Vent. 10: 383-390.

Li, A.G., Zhao, Y.J., Wang, Z.H. and Gao, R. (2014). Capture and containment efficiency of the exhaust hood in a typical Chinese commercial kitchen with air curtain ventilation. Int. J. Vent. 13: 221-234.

Li, T.X., Cao, S.Z., Fan, D.L., Zhang, Y.Q., Wang, B.B., Zhao, X.G., Leaderer, B.P., Shen, G.F., Zhang, Y.W. and Duan, X.L. (2010). Household concentrations and personal exposure of $\mathrm{PM}_{2.5}$ among urban residents using different cooking fuels. Sci. Total Environ. 6: 548-549.

Li, Y. and Delsante, A. (1996). Derivation of capture efficiency of kitchen range hoods in a confined space. Build. Environ. 31: 461-468.

Li, Y.C., Shu, M., Ho, S.S.H., Wang, C., Cao, J.J., Wang, G.H., Wang, X.X., Wang, K. and Zhao, X.Q. (2015). Characteristics of $\mathrm{PM}_{2.5}$ emitted from different cooking activities in China. Atmos. Res. 166: 83-91.

Li, Y.Y., Yang, L.X., Chen, X.F., Gao, Y., Jiang, P., Zhang, J.M., Yu, H. and Wang, W.X. (2017). $\mathrm{PM}_{2.5^{-}}$ bound PAHs in indoor and outdoor of hotels in urban and suburban of Jinan, China: Concentrations, sources, and health risk impacts. Aerosol Air Qual. Res. 17: 2463-2473.

Li, Z.Y., Fan, L., Wang, L., Ma, H.Q., Hu, Y., Jiang, Y.G., An, C.X., Liu, A.Q., Han, J.B. and Jin, H. (2018). PAH profiles of emitted ashes from indoor biomass burning across the Beijing-Tianjin-Hebei region and implications on source identification. Aerosol Air Qual. Res. 18: 749761.

Lim, K. and Lee, C. (2008). A numerical study on the characteristics of flow field, temperature and concentration distribution according to changing the shape of separation plate of kitchen hood system. Energy Build. 40: 175-184.
Liu, Y.Y., Zhang, W.J., Bai, Z.P., Yang, W., Zhao, X.Y., Han, B. and Wang, X.H. (2017). China source profile shared service (CSPSS): The Chinese $\mathrm{PM}_{2.5}$ database for source profiles. Aerosol Air Qual. Res. 17: 1501-1514.

Livchak, A., Schrock, D. and Sun, Z. (2005). The effect of supply air systems on kitchen thermal environment. ASHRAE Trans. 111: 748-54.

Lombardi-Boccia, G., Lanzi, S. and Aguzzi, A. (2004). Aspects of meat quality: Trace elements and B vitamins in raw and cooked meats. J. Food Compos. Anal. 18: 39-46.

Lu, F.J., Shen, B.X., Yuan, P., Li, S.H., Sun, Y.T. and Mei, X. (2019). The emission of $\mathrm{PM}_{2.5}$ in respiratory zone from Chinese family cooking and its health effect. Sci. Total Environ. 654: 671-677.

Lu, S.L., Yao, Z.K., Chen, X.H., Wu, M.H., Sheng, G.Y., $\mathrm{Fu}$, J.M. and Daly, P. (2008). The relationship between physicochemical characterization and the potential toxicity of fine particulates $\left(\mathrm{PM}_{2.5}\right)$ in Shanghai atmosphere. Atmos. Environ. 42: 7205-7214.

Lunden, M.M., Delp, W.W. and Singer, B.C. (2014). Capture efficiency of cooking-related fine and ultrafine particles by residential exhaust hoods. Indoor Air 25: 45-58.

Madsen, U., Breum, O. and Nielsen, P.V. (1994). Local exhaust ventilation-a numerical and experimental study of capture efficiency. Build. Environ. 29: 319-323.

McDonald, J.D., Zielinska, B., Fujita, E.M., Sagebiel, J.C., Chow, J.C. and Watson, J.G. (2003). Emissions from Charbroiling and Grilling of Chicken and Beef. J. Air Waste Manage. Assoc. 53: 185-194.

Ng, T.P., Seet, C.S.R., Tan, W.C. and Foo, S.C. (2001). Nitrogen dioxide exposure from domestic gas cooking and airway response in asthmatic women. Thorax 56: 596-601.

Ni, K., Carter, E. and Schauer, J.J. (2016). Seasonal variation in outdoor, indoor, and personal air pollution exposures of women using wood stoves in the Tibetan Plateau: Baseline assessment for an energy intervention study. Environ. Int. 94: 449-457.

Oeder, S., Dietrich, S., Weichenmeier, I., Schober, W., Pusch, G., Jörres, R.A., Schierl, R., Nowak, D., Fromme, H., Behrendt, H. and Buters, J.T.M. (2012). Toxicity and elemental composition of particulate matter from outdoor and indoor air of elementary schools in Munich, Germany. Indoor Air 22:148-58.

Oros, D.R. and Simoneit, B.R.T. (2001a). Identification and emission factors of molecular tracers in organic aerosols from biomass burning Part 1. Temperate climate conifers. Appl. Geochem. 16: 1513-1544.

Oros, D.R. and Simoneit, B.R.T. (2001b). Identification and emission factors of molecular tracers in organic aerosols from biomass burning Part 2. Deciduous trees. Appl. Geochem. 16: 1545-1565.

Pei, B., Cui, H.A., Liu, H. and Yan, N.Q. (2016). Chemical characteristics of fine particulate matter emitted from commercial cooking. Front. Environ. Sci. Eng. 10: 559568.

Pekkinen, J. and Takki-Halttunen, T. (1992). Ventilation 
efficiency and thermal comfort in commercial kitchens. ASHRAE Trans. 98: 1214-1218.

Poon, C., Wallace, L. and Lai, A.C.K. (2016). Experimental study of exposure to cooking emitted particles under single zone and two-zone environments. Build. Environ. 104: 122-130.

Public Utilities Board (PUB) (2007). Home Page. https:// www.pub.gov.sg/

Radzi bin Abas, M., Oros, D.R. and Simoneit, B.R.T. (2004). Biomass burning as the main source of organic aerosol particulate matter in Malaysia during haze episodes. Chemosphere 55: 1089-1095.

Rajasekar, A. and Balasubramanian, R. (2011). Assessment of airborne bacteria and fungi in food courts. Build. Environ. 46: 2081-2087.

Rogge, W.F., Hildemann, L.M., Mazurek, M.A., Cass, G.R. and Simoneit, B.R.T. (1991). Sources of fine organic aerosol: I. Charbroilers and meat cooking operations. Environ. Sci. Technol. 25: 1112-1125.

Rogge, W.F., Hildemann, L.M., Mazurek, M.A., Cass, G.R. and Simoneit, B.R.T. (1993). Sources of fine organic aerosol. 4. Particulate abrasion products from leaf surfaces of urban plants. Environ. Sci. Technol. 27: 2700-2711.

Saito, E., Tanaka, N., Miyazaki, A. and Tsuzaki, M. (2014). Concentration and particle size distribution of polycyclic aromatic hydrocarbons formed by thermal cooking. Food Chem. 153:285-291.

Schauer, J.J., Kleeman, M.J., Cass, G.R. and Simoneit, B.R.T. (1999). Measurement of emissions from air pollution sources. 1. $\mathrm{C}_{1}$ through $\mathrm{C}_{29}$ organic compounds from meat charbroiling. Environ. Sci. Technol. 33: 15661577.

Schauer, J.J. and Cass, G.R. (2000). Source apportionment of winter time gas-phase and particle-phase air pollutants using organic compounds as tracers. Environ. Sci. Technol. 34: 1821-1832.

Schauer, J.J., Kleeman, M.J., Cass, G.R. and Simoneit, B.R.T. (2002). Measurement of emissions from air pollution sources. 4. $\mathrm{C}_{1}-\mathrm{C}_{27}$ organic compounds from cooking with seed oils. Environ. Sci. Technol. 36: 567575.

See, S.W. and Balasubramanian, R. (2006). Physical characteristics of ultrafine particles emitted from different gas cooking methods. Aerosol Air Qual. Res. 6: 82-92.

See, S.W., Karthikeyan, S. and Balasubramanian, R. (2006). Health risk assessment of occupational exposure to particulate-phase polycyclic aromatic hydrocarbons associated with Chinese, Malay and Indian cooking. $J$. Environ. Monit. 8: 369-376.

See, S.W. and Balasubramanian, R. (2008). Chemical characteristics of fine particles emitted from different gas cooking methods. Atmos. Environ. 42: 8852-8862.

Seow, A., Poh, W.T., Teh, M., Eng, P., Wang, Y.T., Tan, W.C., Yu, M.C. and Lee, H.P. (2000). Fumes from meat cooking and lung cancer risk in Chinese women. Cancer Epidemiol. Biomarkers Prev. 9: 1215-1221.

Shahid, I., Kistler, M, Shahid, M.Z. and Puxbaum, H.
(2019). Aerosol chemical characterization and contribution of biomass burning to particulate matter at a residential site in Islamabad, Pakistan. Aerosol Air Qual. Res. 19: 148-162.

Sharma, R. and Balasubramanian, R. (2018). Sizefractionated particulate matter in indoor and outdoor environments during the 2015 haze in Singapore: Potential human health risk assessment. Aerosol Air Qual. Res. 18: 904-917.

Sharma, D. and Jain, S. (2019). Impact of intervention of biomass cookstove technologies and kitchen characteristics on indoor air quality and human exposure in rural settings of India. Environ. Int. 123: 240-255.

Shields, P.G., Xu, G.X., Blot, W.J., Fraumeni, J.F.J., Trivers, G.E., Pellizzari, E.D., Qu, Y.H., Gao, Y.T. and Harris, C.C. (1995). Mutagens from heated Chinese and US cooking oils. J. Natl. Cancer Inst. 87: 836-841.

Siddiqui, A.R., Lee, K., Bennett, D., Yang, X., Brown, K.H., Bhutta, Z.A. and Gold, E.B. (2009). Indoor carbon monoxide and $\mathrm{PM}_{2.5}$ concentrations by cooking fuels in Pakistan. Indoor Air 19: 75-82.

Simoneit, B.R.T. (1986). Characterization of organicconstituents in aerosols in relation to their origin and transport: A review. Int. J. Environ. Anal. Chem. 23: 207-237.

Singer, B.C., Delp, W.W. and Apte, M.G. (2012). Experimental evaluation of installed cooking exhaust fan performance. Lawrence Berkeley National Laboratory, USA.

Singh, A., Kamal, R. and Mudiam, M.K.R. (2006). Heat and PAHs emissions in indoor kitchen air and its impact on kidney dysfunctions among kitchen workers in Lucknow, North India. J. Environ. Monit. 8: 369-376.

Sjaastad, A.K. and Svendsen, K. (2008). Exposure to mutagenic aldehydes and particulate matter during panfrying of beefsteak with margarine, rapeseed oil, olive oil or soybean oil. Ann. Occup. Hyg. 52: 739-745.

Sjaastad, A.K., Svendsen, K. and Jørgensen, R.B. (2008). Sub-micrometer particles - their level and spreading after pan frying of beefsteak. Indoor Built Environ. 17: 230-236.

Sjaastad, A.K. and Svendsen, K. (2010). Different types and settings of kitchen canopy hoods and particulate exposure conditions during pan-frying of beefsteak. Indoor Built Environ. 19: 267-274.

Smith, V.A., Swierczyna, R.T. and Claar, C.N. (1995). Application and enhancement of the standard test method for the performance of commercial kitchen ventilation systems. ASHRAE Trans. 101: 594-605.

Sofuoglu, S.C., Toprak, M., Inal1, F. and Cimrin, A.H. (2015). Indoor air quality in a restaurant kitchen using margarine for deep-frying. Environ. Sci. Pollut. Res. 22: 15703-15711.

Stabile, L., Fuoco, F.C., Marini, S. and Buonanno, G. (2015). Effects of the exposure to indoor cookinggenerated particles on nitric oxide exhaled by women. Atmos. Environ. 103: 238-246.

Subramanian, R. and Nakajima, M. (1997). Membrane degumming of crude soybean and rapeseed oils. J. Am. 
Oil Chem. Soc. 74: 971-975.

Svendsen, K., Jensen, H.N., Sivertsen, I. and Sjaastad, K. (2002). Exposure to cooking fumes in restaurant kitchens in Norway. Ann Occup Hyg. 46: 395-400.

Swierczyna, R.T., Smith, V.A. and Schmid, F.P. (1997). New threshold exhaust flow rates for capture and containment of cooking effluent. ASHRAE Trans. 103: 943-949.

Swierczyna, R. (2006). Effects of appliance diversity and position on commercial kitchen hood performance. ASHRAE Trans. 112: 591-602.

Taner, S., Pekey, B. and Pekey, H. (2013). Fine particulate matter in the indoor air of barbeque restaurants: Elemental compositions, sources and health risks. Sci. Total Environ. 454-455: 79-87.

Tiwari, M., Sahu, S.K. and Pandit, G.G. (2015). Inhalation risk assessment of PAH exposure due to combustion aerosols generated from household fuels. Aerosol Air Qual. Res. 15: 582-590.

To, W.M. and Yeung, L.L. (2011). Effect of fuels on cooking fume emissions. Indoor Built Environ. 20: 555563.

Torkmahalleh, M.A., Goldasteh, I., Zhao, Y., Udochu, N.M., Rossner, A., Hopke, P.K. and Ferro, A.R. (2012). $\mathrm{PM}_{2.5}$ and ultrafine particles emitted during heating of commercial cooking oils. Indoor Air 22: 483-491.

Torkmahalleh, M.A., Zhao, Y., Hopke, P.K., Rossner, A. and Ferro, A.R. (2013). Additive impacts on particle emissions from heating low emitting cooking oils. Atmos. Environ. 74: 194-198.

Tsai, F.C. and Hsieh, R.H. (2006). Oblique effects on the capture ability of a hood under crosswind environmentsnumerical method. Build. Environ. 41: 1471-1477.

U.S. EPA (1994). Methods for derivation of inhalation reference concentrations and application of inhalation dosimetry, office of health and environmental assessment. Environmental Criteria and Assessment Office Research Triangle Park, NC.

VDI 2052 (1999). Ventilation Requirement for kitchens. Düsseldorf: Verein Deutscher Ingenieure.

Wallace, L.A., Emmerich, S.J. and Howard-Reed, C. (2004). Source strengths of ultrafine and fine particles due to cooking with a gas stove. Environ. Sci. Technol. 38: 2304-2311.

Wallace, L., Wang, F., Howard-Reed, C. and Persily, A. (2008). Contribution of gas and electric stoves to residential ultrafine particle concentrations between 2 and $64 \mathrm{~nm}$ : Size distributions and emission and coagulation remission and coagulation rates. Environ. Sci. Technol. 42: 8641-8647.

Wallace, L. and Ott, W. (2011). Personal exposure ultrafine particles. J. Exposure Sci. Environ. Epidemiol. 21: 2030.

Wan, M.P., Wu, C.L., To, G.N.S., Chan, T.C. and Chao, C.Y.H. (2011). Ultrafine particles, and $\mathrm{PM}_{2.5}$ generated from cooking in homes. Atmos. Environ. 45: 6141-6148.

Wang, C.Y., Liu, L.F., Liu, X.L., Chen, W.J. and He, G.P. (2017). Mechanisms of lung cancer caused by cooking fumes exposure: A minor review. Chin. Med. Sci. J. 32:
193-197.

Wang, G., Cheng, S.Y., Wei, W., Wen, W., Wang, X.Q. and Yao, S. (2015). Chemical characteristics of fine particles emitted from different Chinese cooking styles. Aerosol Air Qual. Res. 15: 2357-2366.

Wang, L.N., Zheng, X.R., Stevanovic, S., Wu, X., Xiang, Z.Y., Yu, M.Z. and Liu, J. (2018). Characterization particulate matter from several Chinese cooking dishes and implications in health effects. J. Environ. Sci. 72: 100-108.

Wang, Q., Shao, M., Zhang, Y., Wei, Y., Hu, M. and Guo, S. (2009). Source apportionment of fine organic aerosols in Beijing. Atmos. Chem. Phys. 9: 8573-8585.

Wang, S. and Zhao, Y. (2011). Air pollution and lung cancer risks. In Encyclopedia of environmental health, Nriagu, J.O. (Ed.), Elsevier, Burlington, pp. 26-38.

Wheeler, A.J., Wallace, L.A., Kearney, J., Van, Ryswyk, K., You, H.Y., Kulka, R., Brook J.R. and Xu, X.H. (2011). Personal, indoor, and outdoor concentrations of fine and ultrafine particles using continuous monitors in multiple residences. Aerosol Sci. Technol. 45: 1078-1089.

Wolbrink, D.W. and Sarnosky, J.R. (1992). Residential kitchen ventilation-S guide for the specifying engineer. ASHRAE Trans. 98: 1187-1198.

Wong, T.W., Wong, A.H.S., Lee, F.S.C. and Qiu, H. (2011). Respiratory health and lung function in Chinese restaurant kitchen workers. Occup. Environ. Med. 68: 746-52.

World Health Organization (WHO) (2010). WHO guidelines for indoor air quality: Selected pollutants. World Health Organization, Geneva.

World Health Organization (WHO) (2014). Public health, environmental and social determinants of health (PHE). World Health Organization, Geneva.

Xiang, Z., Wang, H., Stevanovic, S., Jing, S., Lou, S., Tao, S., Li, L., Liu, J., Yu, M. and Wang, L. (2017). Assessing impacts of factors on carbonyl compounds emissions produced from several typical Chinese cooking. Build. Environ. 125: 348-355.

Xiao, Q.Y., Saikawa, E., Yokelson, R.J., Chen, P.F., Li, C.L. and Kang, S.C. (2015). Indoor air pollution from burning yak dung as a household fuel in Tibet. Atmos. Environ. 102: 406-412.

Xu, H., Li, Y., Guinot, B., Wang, J., He, K., Ho, K.F., Cao, J., Shen, Z., Sun, J., Lei, Y., Gong, X. and Zhang, T. (2018). Personal exposure of $\mathrm{PM}_{2.5}$ emitted from solid fuels combustion for household heating and cooking in rural Guanzhong Plain, northwestern China. Atmos. Environ. 185: 196-206.

Yeung, L.L. and To, W.M. (2008). Size distributions of the aerosols emitted from commercial cooking processes. Indoor Built Environ. 17: 220-229.

Yu, K.P., Yang, K.R., Chen, Y.C., Gong, G.Y., Chen, Y.P., Shih, H.C. and Lung, S.C.C. (2015). Indoor air pollution from gas cooking in five Taiwanese families. Build. Environ. 93: 258-266.

Zhang, J.F. and Smith, K.R. (1999). Emissions of carbonyl compounds from various cook stoves in China. Environ. Sci. Technol. 33: 2311-2320. 
Zhang, N., Han, B., He, F., Xu, J., Zhao, R.J., Zhang, Y.J. and Bai, Z.P. (2017). Chemical characteristic of $\mathrm{PM}_{2.5}$ emission and inhalational carcinogenic risk of domestic Chinese cooking. Environ. Pollut. 227: 24-30.

Zhang, Q., Gangupomu, R.H., Ramirez, D. and Zhu, Y. (2010). Measurement of ultrafine particles and other air pollutants emitted by cooking activities. Int. J. Environ. Res. Public Health 7: 1744-1759.

Zhao, P., Yu, K.P. and Lin, C.C. (2011). Risk assessment of inhalation exposure to polycyclic aromatic hydrocarbons in Taiwanese workers at night markets. Int. Arch Occup. Environ. Health 84: 231-237.

Zhao, X.Y., Hu, Q.H., Wang, X.M., Ding, X., He, Q.F., Zhang, Z., Shen, R.Q., Lü, S.J., Liu, T.Y., Fu, X.X. and Chen, L.G. (2015). Composition profiles of organic aerosols from Chinese residential cooking: Case study in urban Guangzhou, south China. J. Atmos. Chem. 72: 118.

Zhao, Y., Hu, M., Slanina, S. and Zhang, Y. (2007a). Chemical compositions of fine particulate organic matter emitted from Chinese cooking. Environ. Sci. Technol. 41: 99-105.

Zhao, Y., Hu, M., Slanina, S. and Zhang, Y. (2007b). The molecular distribution of fine particulate organic matter emitted from Western-style fast food cooking. Atmos. Environ. 41: 8163-8171.

Zhao, Y., Li, A., Tao, P. and Gao, R. (2013). The impact of various hood shapes, and side panel and exhaust duct arrangements, on the performance of typical Chinese style cooking hoods. Build. Simul. 6: 139-149.

Zhao, Y.J., Chen, C. and Zhao, B. (2018). Is oil temperature a key factor influencing air pollutant emissions from Chinese cooking? Atmos. Environ. 193: 190-197.

Zhao, Y.J., Chen, C. and Zhao, B. (2019). Emission characteristics of $\mathrm{PM}_{2.5}$-bound chemicals from residential Chinese cooking. Build. Environ. 149: 623-629.

Zhou, B., Chen, F., Dong, Z.B. and Nielsen, P.V. (2016). Study on pollution control in residential kitchen based on the push-pull ventilation system. Build. Environ. 107: 99-112.

Zhou, B., Wei, P., Tan, M.L., Xu, Y., Ding, L.L., Mao, X.Y., Zhao, Y.K. and Kosonen, R. (2019). Capture efficiency and thermal comfort in Chinese residential kitchen with push-pull ventilation system in winter-A field study. Build. Environ. 149: 182-195.

Zhu, L.Z. and Wang, J. (2003). Sources and patterns of polycyclic aromatic hydrocarbons pollution in kitchen air, China. Chemosphere 50: 611-618.

Ziane, R. (2007). Halton design guide for indoor air climate in commercial kitchen. Third edition. Halton foodservice.

Received for review, April 11, 2019

Revised, July 10, 2019

Accepted, July 16, 2019 